Research Article

\title{
Experimental Investigation on the Behavior of Bracing Damper Systems by Utilizing Metallic Yielding and Recentering Material Devices
}

\author{
Jong Wan Hu $\mathbb{D}^{1,2}$ Myoung-hyun Noh $\mathbb{D}^{3},{ }^{3}$ and Jun-hyuck Ahn ${ }^{1,2}$ \\ ${ }^{1}$ Department of Civil and Environmental Engineering, Incheon National University, 12-1 Songdo-dong, Yeonsu-gu, Incheon \\ 22012, Republic of Korea \\ ${ }^{2}$ Incheon Disaster Prevention Research Center, Incheon National University, 12-1 Songdo-dong, Yeonsu-gu, Incheon 22012, \\ Republic of Korea \\ ${ }^{3}$ POSCO Product Application Center, 180-1 Songdo-dong, Yeonsu-gu, Incheon 22012, Republic of Korea
}

Correspondence should be addressed to Myoung-hyun Noh; mnoh@posco.com

Received 30 July 2017; Revised 26 November 2017; Accepted 10 December 2017; Published 30 January 2018

Academic Editor: Carlos Garcia-Mateo

Copyright (C) 2018 Jong Wan Hu et al. This is an open access article distributed under the Creative Commons Attribution License, which permits unrestricted use, distribution, and reproduction in any medium, provided the original work is properly cited.

\begin{abstract}
With the aim of effectively reducing the structural damage caused by earthquake events, bracing systems equipped with retrofitting damper devices, which take advantage of the energy dissipation and impact absorption, have been widely used in practical construction sites. These bracing dampers, however, have been recognized as expendable supplies for easily replacing the damaged ones after a strong earthquake because they are commonly designed to undergo concentrated force and deformation for the purpose of protecting the main structural members such as the columns and beams. In this paper, the use of new superelastic shape memory alloy (SMA) dampers that can partially recover their original configuration is proposed to decrease the repair cost. In addition, the conventional steel dampers used for improving the energy dissipation arising due to metallic yielding are additionally integrated into the bracing member. The behaviors of such bracing systems with the damper devices were reproduced in experimental tests with the cyclic loading history, and then their strength capacity and recentering capability were estimated based on the experiment results. Finally, additional experimental tests were performed by imposing cyclic loading histories with different loading speeds on the superelastic SMA and steel plate damper specimens.
\end{abstract}

\section{Introduction}

The bracing members capable of active control against seismic loads in an effort to reduce earthquake damage have been widely utilized in construction sites. The typical seismic isolators, which are used to mitigate the acceleration transmitted from the ground, are placed in low- to midrise buildings because they are commonly installed to withstand the load of the entire structure [1-3]. On the other hand, damper devices, which attenuate the vibration caused by energy dissipation, are integrated with the bracing member in the structure and have been widely used in low- to high-rise frame buildings without height limits [4-6]. In the case of a severe earthquake event, structural damage to the main members (e.g., beams and columns) directly supporting the self-weight of the frame building may cause the collapse of the entire structure. Therefore, for the purpose of protecting such main members, the damper devices installed on the bracing member are designed to concentrate the displacement and load and have been used as consumable products that can be easily replaced when damaged [7-9]. Although the conventional bracing damper system has an excellent ability not only to absorb the external impact but also to diminish the structural vibration, it has the disadvantage of requiring additional maintenance due to the residual deformation caused by the lack of recentering capability [10-14]. Accordingly, this paper proposes new 


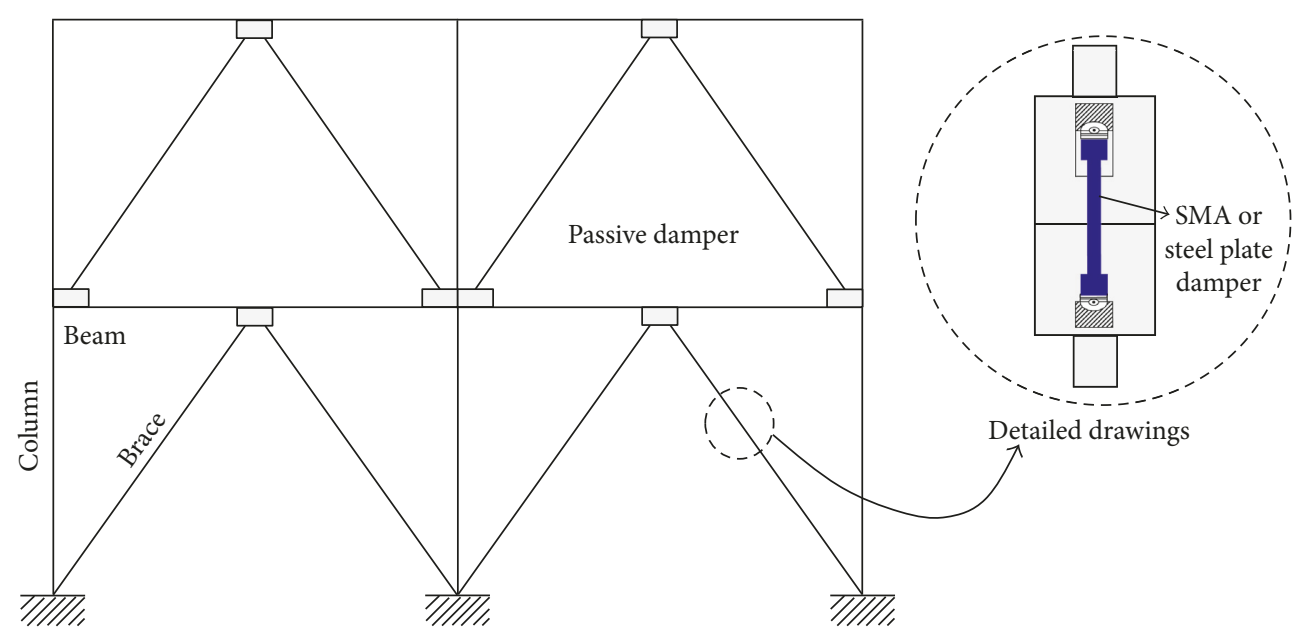

FIgURE 1: Schematic drawing for the bracing damper systems.

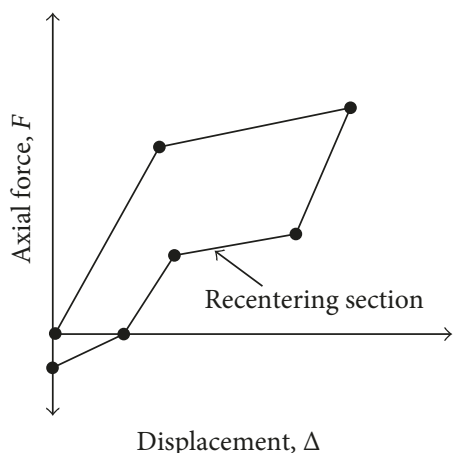

(a)

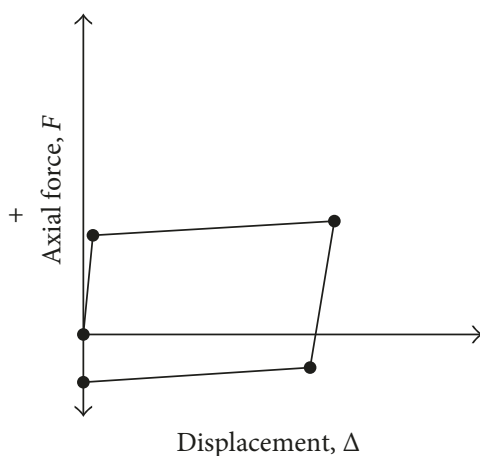

(b)

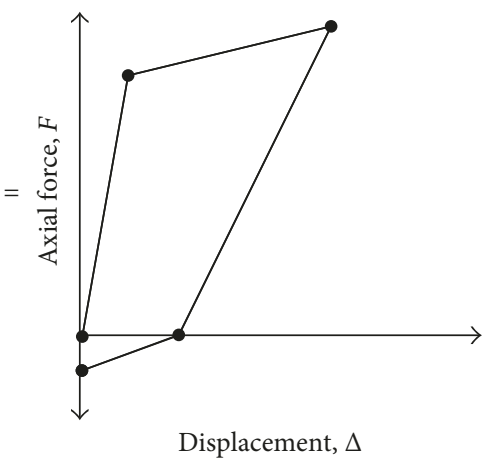

(c)

Figure 2: Response mechanism. (a) SMA behavior. (b) Steel behavior. (c) Total behavior.

bracing damper systems that can effectively reduce the residual displacement by installing seismic retrofit devices to enhance the recentering capability of the bracing member.

The superelastic shape memory alloys (SMAs) maintain their austenite properties even at room temperature and can be restored to their original shape only after the removal of stress, even if no heat treatment is applied [15-17]. The most widely used among them is the Nitinol material fabricated by mixing titanium and nickel, and which exhibits flag-shaped hysteresis behavior that nearly recovers the original configuration even if the applied strain is $6-8 \%$, depending on the composite ratio between the two materials $[15,18,19]$. Recently, owing to this unique material property, the superelastic SMAs began to be utilized as the retrofitting systems, such as bracing dampers and displacement control devices, with the aim of mitigating earthquake damage. Once superelastic SMA dampers are integrated in the bracing member, the force and deformation are likely to concentrate on these dampers, thereby playing an important role in dramatically reducing the residual deformation in the frame structure [20-22]. For this reason, new bracing damper systems fabricated with superelastic SMA plates are introduced, and additional damper models in combination with steel plate dampers are also proposed to improve the energy dissipation as well as the load resistance capacity.

In this study, prototypes were constructed for these bracing dampers, and then experimental tests were conducted with a constant loading speed to reproduce their behavior. Basically, bracing damper systems are constructed by connecting two hollow box members with superelastic SMA plates. The other bracing damper systems are also constructed by adding steel plates connecting two box members in combination with superelastic SMA plates. The strength and residual displacement were intended to be observed through the experimental tests while the number of steel plates was constantly increased. Furthermore, the changes in the degrees of stiffness and residual displacement were measured by applying load histories with different loading speeds to the steel and superelastic SMA plate specimens. It was shown that the behavior of the bracing damper system subjected to an earthquake load could be predicted through these experimental specimen tests. As a result, the experimental specimen tests indicated that the bracing damper system proposed in this study is superior to the conventional steel damper in terms of strength capacity and recentering capability. 


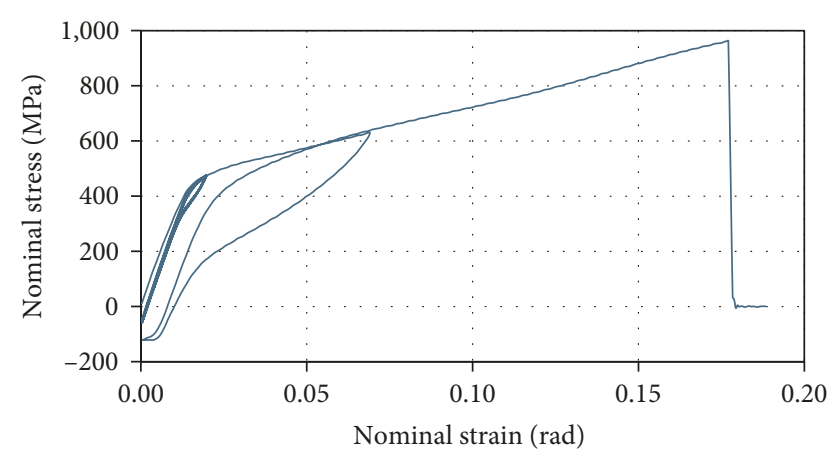

Figure 3: Stress and strain curves for superelastic shape memory alloys $(0.033 \mathrm{~mm} / \mathrm{sec}$ loading speed).

\section{Design Philosophy and Experimental Models}

The bracing members are generally installed in the perimeter moment-resisting frame, which results in a skeleton in the building, and provide extra rigidity for the frame structure so that it could effectively resist the lateral loads caused by typhoons and earthquakes [10, 22-26]. These bracing members are mainly connected to the gusset plates situated between the end of the column and the center of the beam, in the form of a pin joint in which the bending moment is released by bolts. Thus, they are considered subjected to only uniaxial member force such as tension and compression. Figure 1 shows the concentrically inverted V-braced frame structure with a pair of bracing members in one span. The superelastic SMA or conventional steel plate dampers are installed at the center of the bracing member, as shown in the figure. The inverted $\mathrm{V}$-shaped bracing members generate an axial force mainly for the load acting on the side to withstand, and a pair of bracing members alternate between tension and compression. As each of the plate dampers connects two separate hollow box-type bracing members, when systematic compression is applied, the bracing damper systems are not subjected to axial force. At this time, only bearing pressure occurs at the contact face between the two box-type bracing members. In the bracing member subjected to tension, however, tensile force is generated in the bracing damper systems, and a relatively large amount of displacement occurs. Therefore, the displacement is concentrated on the bracing damper installed on the inverted $\mathrm{V}$-shaped bracing member subjected to tension, and then a considerable amount of recentering force may be generated when the applied load is removed. Applying this design principle, this study investigated the cyclic behavior of the bracing damper system under tension only, not including bearing compression.

Figure 2 shows the expected behavior of the bracing damper system when tension is applied. In the case where a steel plate damper is used, the total behavior of the bracing damper system is displayed in parallel with the behavior of the superelastic SMA plate damper. The superelastic SMA exhibits recentering behavior upon unloading and can partially restore its original configuration. During the unloading, superelastic SMA plate dampers provide recentering force to the bracing

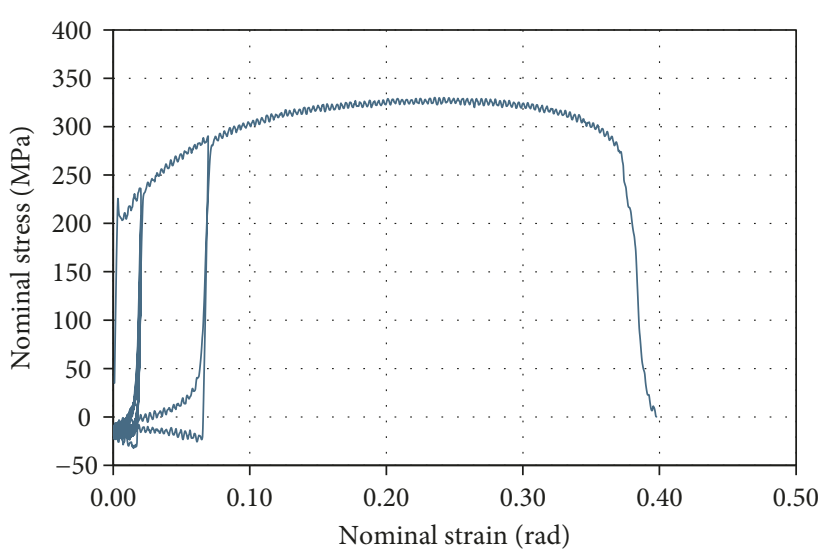

FIgURE 4: Stress and strain curves for general carbon steel $(0.033 \mathrm{~mm} / \mathrm{sec}$ loading speed $)$.

member and thus reduce the occurrence of a significant amount of residual deformation compared with the general steel plate dampers. In the total behavior of the bracing damper system, the steel plate dampers play a role mainly in enhancing the strength and energy dissipation capacity. In this study, the number of superelastic SMA dampers was fixed while the number of steel plate dampers was increased to observe the changes in the strength performance and recentering capability in the total behavior.

\section{Material Properties}

Figures 3 and 4 show the stress and strain curves of the superelastic SMA plate and the steel plate, respectively, obtained in accordance with the American Society for Testing and Materials (ASTM) guidelines so as to confirm the material property $[27,28]$. In this study, SS400 steel, a common carbon steel, was used for steel. Loads were applied to the 0.02 and 0.07 radian target strains and were deformed until fracture occurred. The loading speed was a static load of $0.033 \mathrm{~mm} / \mathrm{sec}$ for both the specimens.

The superelastic SMA that was used in this study was a metal alloy of nickel and titanium (also known as Nitinol), in which the two constituent elements were presented with roughly equal atomic percentages. The compositions of all the SMA material samples were nearly identical, with an average of $55 \%$ nickel by weight and $45 \%$ titanium. The austenite start temperature $\left(A_{\mathrm{s}}\right)$ ranged from about -15 to $-10^{\circ} \mathrm{C}$. In this study, the material tests, which could obtain the stress and strain curves of the superelastic SMAs, were conducted under room temperature $\left(25^{\circ} \mathrm{C}\right)$. The initial slope of the superelastic SMA plate, which indicates the elastic modulus, is more sluggish than that of the conventional steel plate, and it can be seen in Figure 3 that the 0.02 radian strain was restored to its original shape upon unloading. Both martensite phase transformation and strain hardening begin to occur at the $450 \mathrm{MPa}$ stress, similar to the yield point of ordinary metals. Approximately $620 \mathrm{MPa}$ stress can be generated at the 0.07 radian strain, and austenite phase transformation occurs at the time of removal of the load. Finally, this SMA plate produces only 0.015 radian residual 

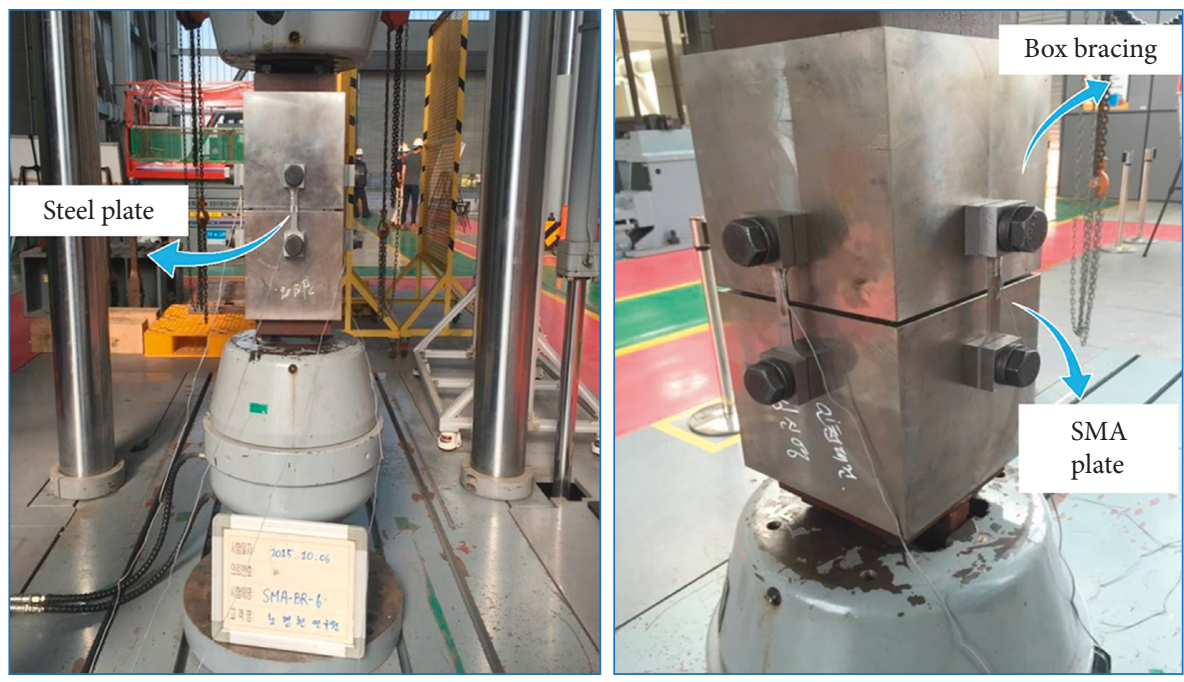

FIGURE 5: Experimental test setup.

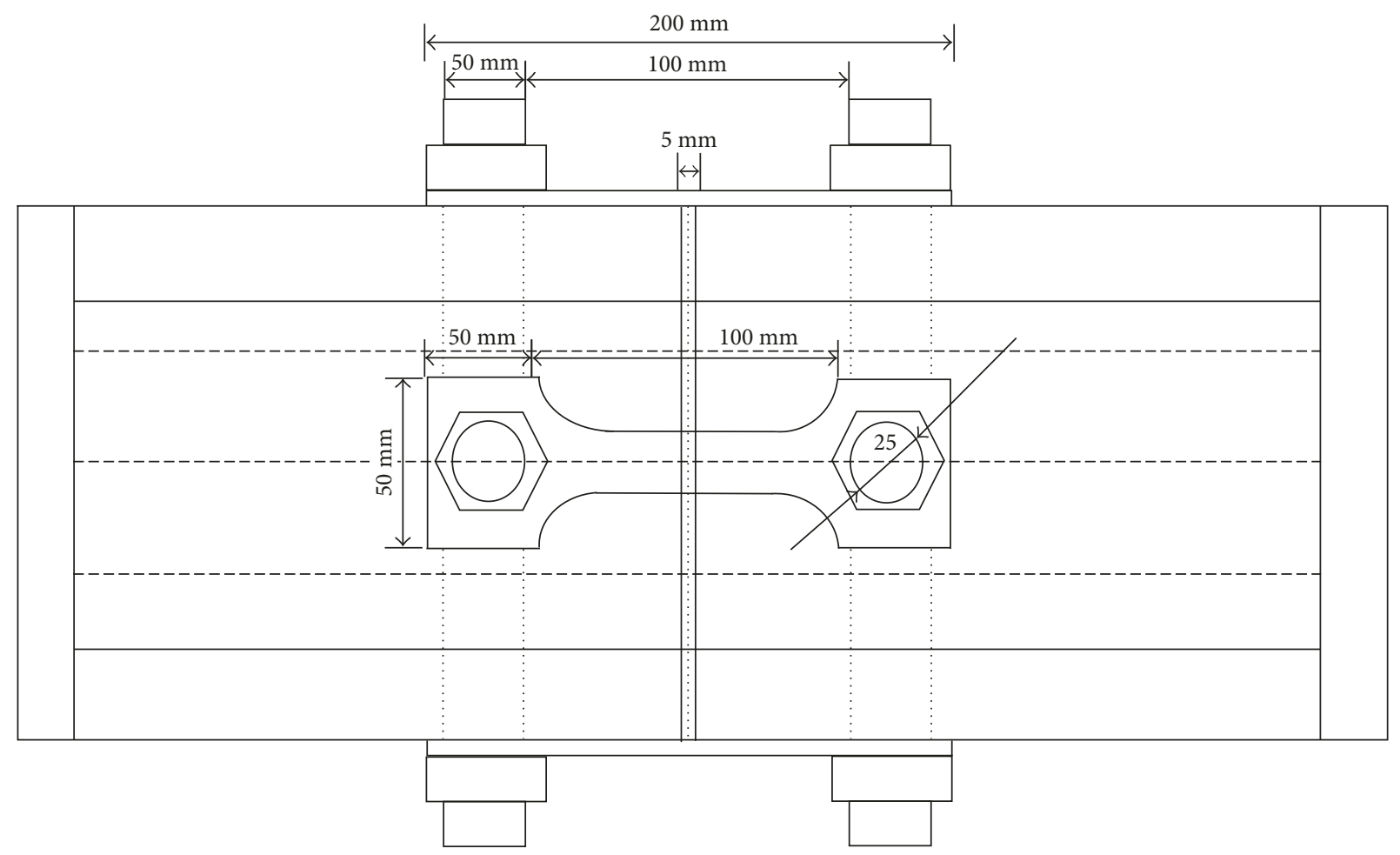

Figure 6: Detailed sizes of experimental models.

strain upon unloading, and thus, a strain recovery phenomenon is observed. The residual strain of the superelastic SMA plate is gradually augmented with the increase in the loading strain. The ultimate stress of $960 \mathrm{MPa}$ takes place due to strain hardening, and sudden fracture occurs at around 0.175 radian strain. The steel plate shows the typical isotropic hardening behavior, in which the initial slope is the same as the unloading slope, resulting in nearly zero strain recovery and considerable residual strain during unloading. After yielding, the maximum stress of about $320 \mathrm{MPa}$ is observed at the near 0.25 radian strain, and thereafter, the stress is decreased until fracture occurs at the 0.35 radian strain. Accordingly, it is possible to secure energy dissipation capacity through ductility and metallic yielding in the behavior of the carbon steel material.

\section{Experimental Test Setup}

For the purpose of reproducing the behavior of the bracing damper systems proposed herein, experimental models were designed by setting the number of steel plates as a design parameter, and structural tests were carried out using 


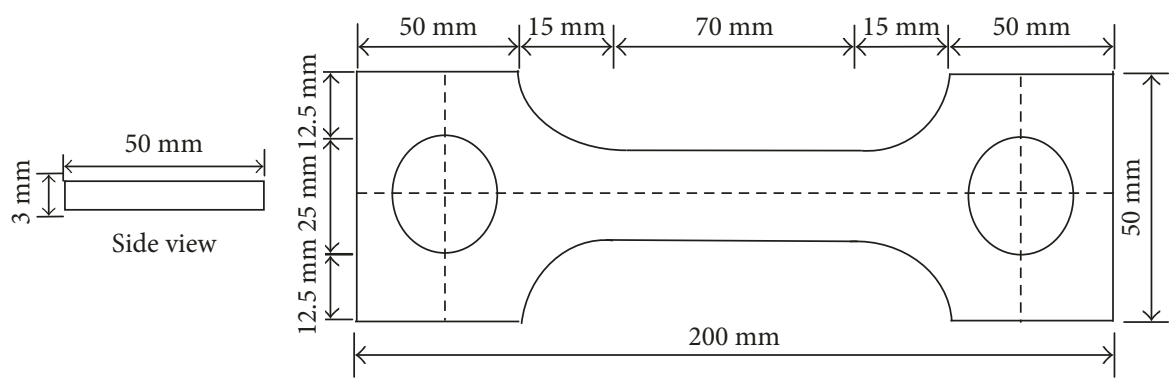

(a)

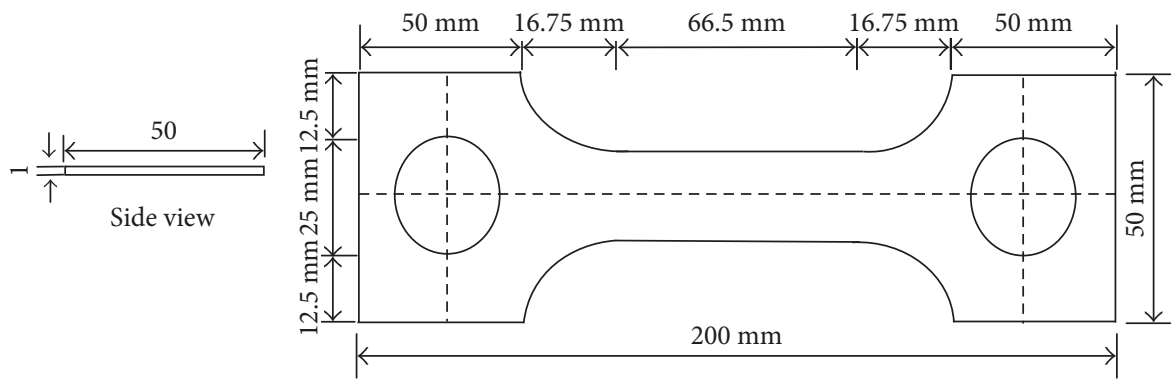

(b)

Figure 7: Sample SMA and steel plates. (a) SMA plate. (b) Steel plate.

TABLE 1: Bracing model cases for the experimental tests.

\begin{tabular}{lcccccccc}
\hline \multirow{2}{*}{ Test name } & \multicolumn{2}{c}{ SS400 $(1 \mathrm{~mm})$} & \multicolumn{2}{c}{ SMA $(3 \mathrm{~mm})$} & \multicolumn{2}{c}{ Loading speed } & \multicolumn{2}{c}{ Temperature } \\
& Left & Right & Left & Right & $\mathrm{mm} / \mathrm{sec}$ & $\mathrm{mm} / \mathrm{min}$ & \multicolumn{2}{c}{$\begin{array}{c}{ }^{\circ} \mathrm{C} \\
\mathrm{R}(\%)\end{array}$} \\
\hline SMA-BR-1 & 0 & 0 & 1 & 1 & 0.033 & 1.98 & Triangular wave & 25.9 \\
SMA-BR-2 & 1 & 1 & 1 & 1 & 0.033 & 1.98 & Triangular wave & 49.5 \\
SMA-BR-3 & 2 & 2 & 1 & 1 & 0.033 & 1.98 & Triangular wave & 26.0 \\
SMA-BR-4 & 3 & 3 & 1 & 1 & 0.033 & 1.98 & Triangular wave 28.0 \\
\hline
\end{tabular}

a hydraulic actuator. Figure 5 presents the test setup for the bracing damper models in the hydraulic actuator for the load test. The presented hydraulic actuators are capable of imposing tensile and compressive loads up to $1000 \mathrm{kN}$ and can be cyclically loaded with displacement control up to $100 \mathrm{~mm}$ of the maximum stroke. In addition, the frequency of the load speed possibly ranges from 0 to $20 \mathrm{~Hz}$. As shown in the figure, superelastic shape memory alloy plate dampers were installed on one side and steel plate dampers were installed symmetrically on the other side. The plate dampers were placed in the center of the box member, and washers were fixed with $25 \mathrm{~mm}$-diameter bolts. The box members were assembled with a $5 \mathrm{~mm}$ clearance distance, as shown in Figure 6 . The bracing dampers are deformed by tensile force mainly because bearing pressure is generated in the box member subjected to compression.

Figure 7 shows the specifications of the superelastic SMA and steel plate dampers. These plate dampers were constructed with variable sections along the longitudinal direction to prevent the occurrence of fracture in the net section area where there is a cross-sectional loss due to the bolt hole. The superelastic SMA and steel plate dampers were designed to have 3 and $1 \mathrm{~mm}$ thicknesses, respectively. As

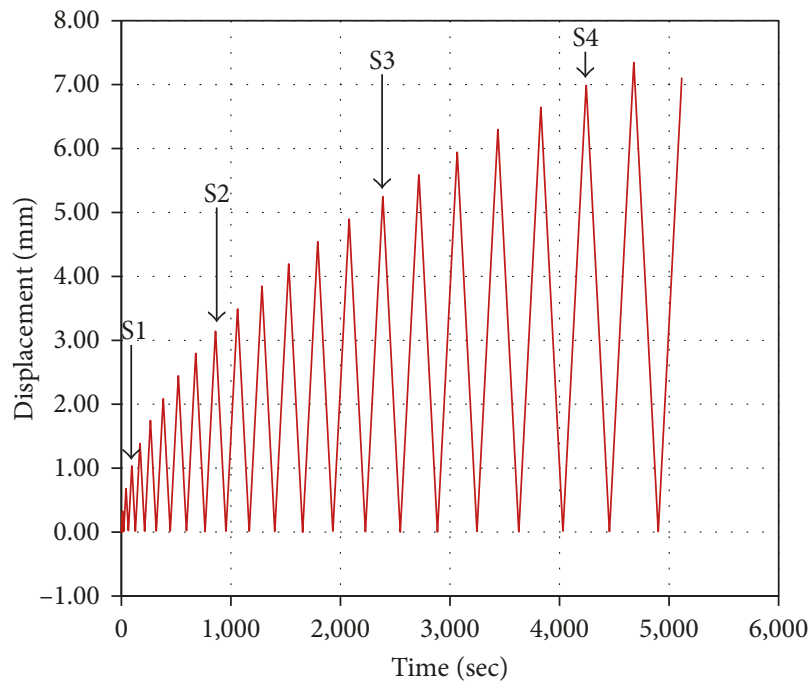

FIGURE 8: Loading histories.

presented in Table 1, each model gradually increased the number of steel plate dampers to fix the number of superelastic shape memory alloy plate dampers and to 

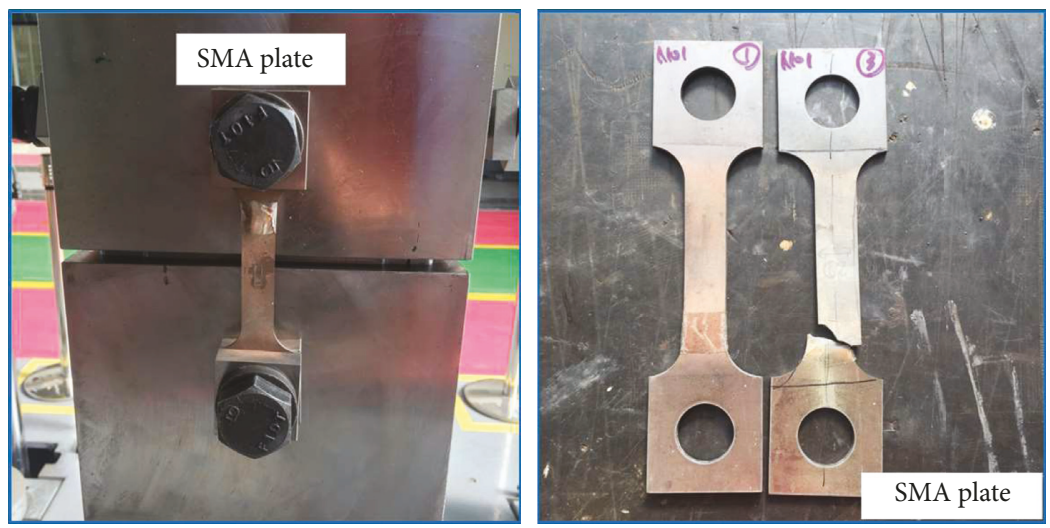

(a)
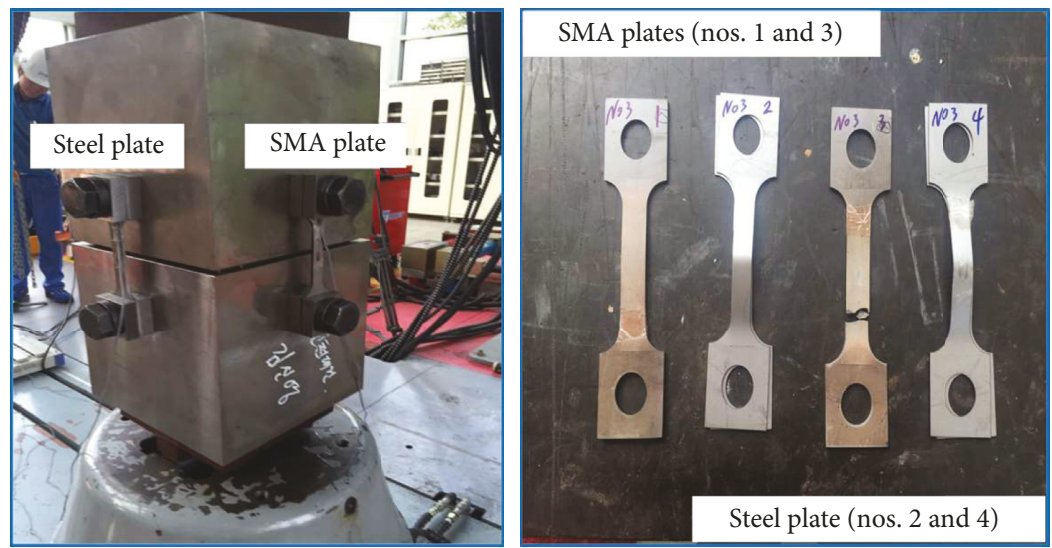

(b)
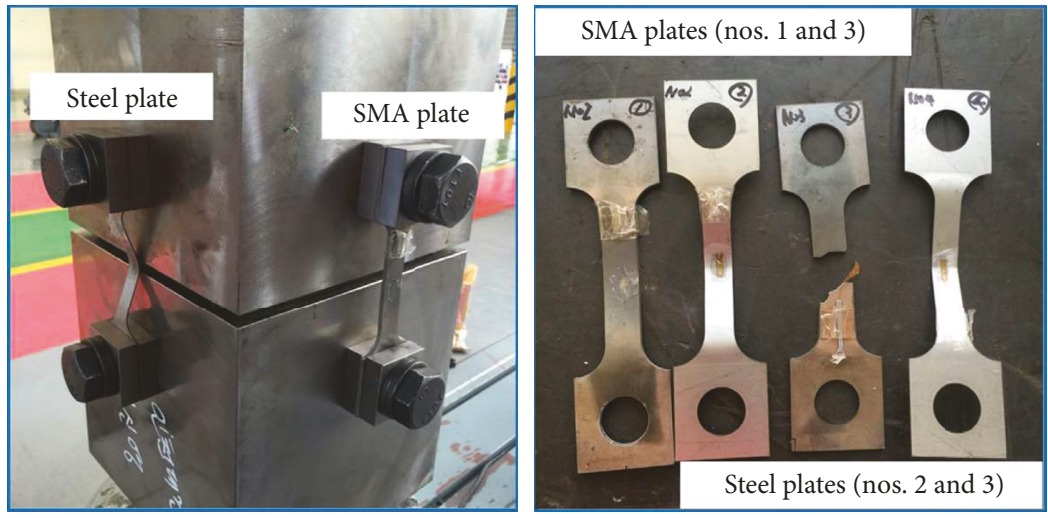

(c)
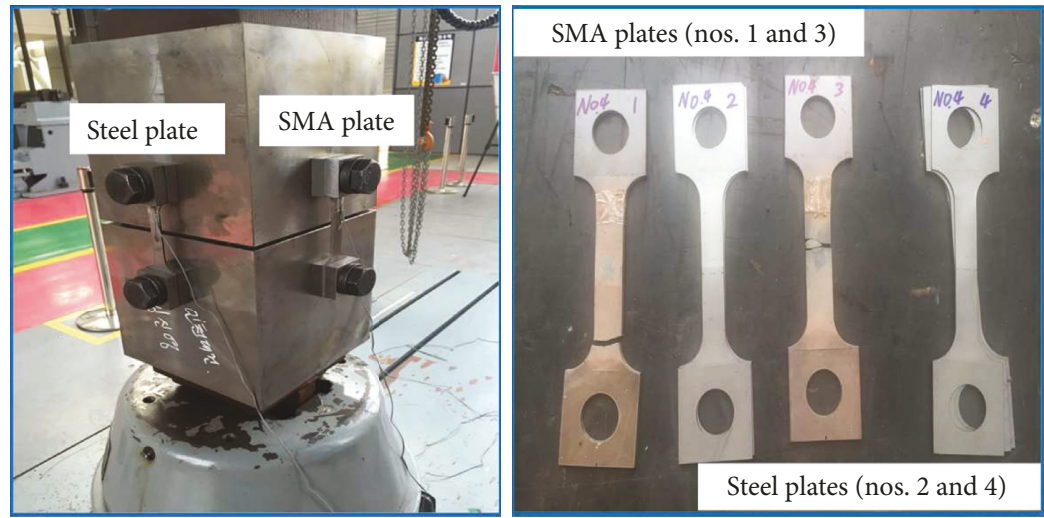

(d)

FIGURE 9: Pictures for experimental results after testing. (a) SMA-BR-1. (b) SMA-BR-2. (c) SMA-BR-3. (d) SMA-BR-4. 


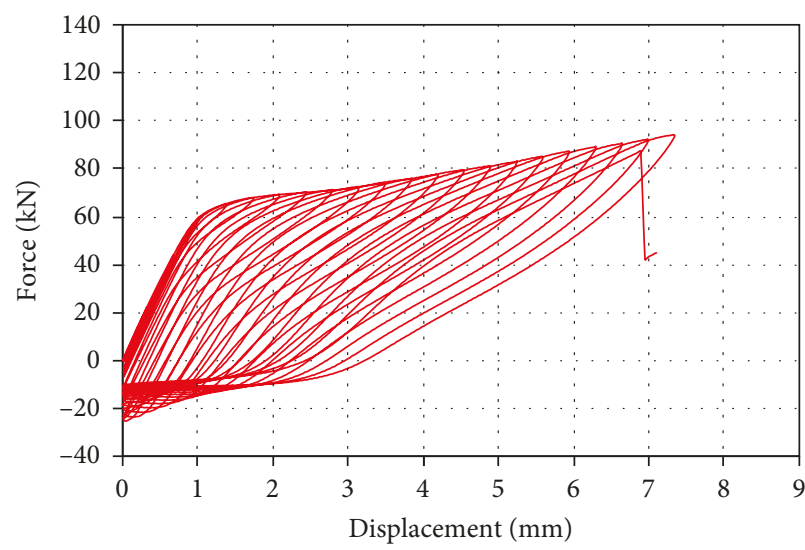

(a)

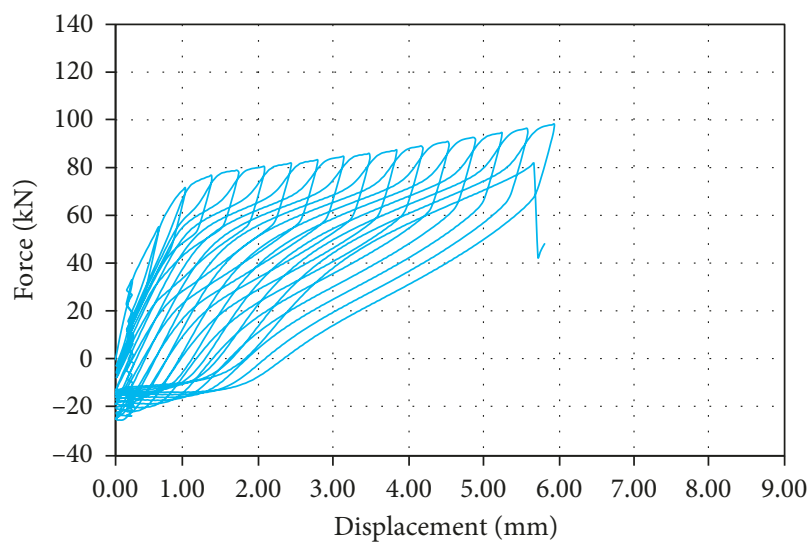

(c)

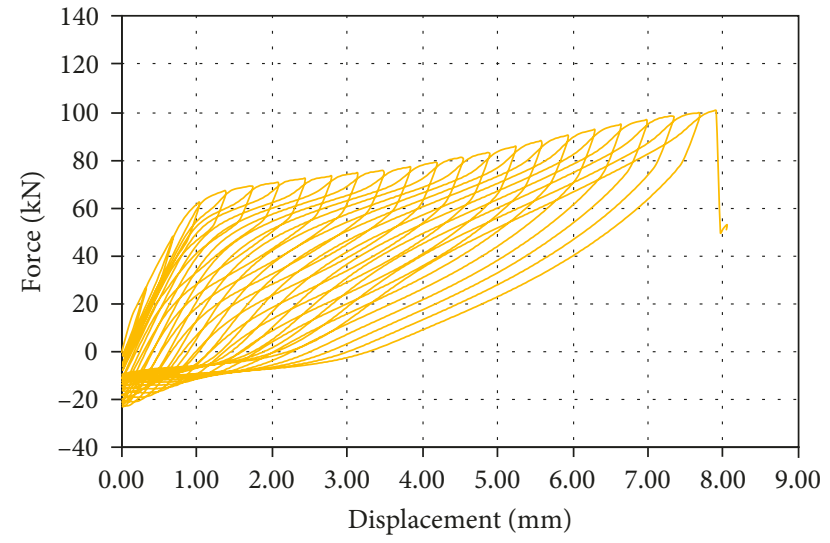

(b)

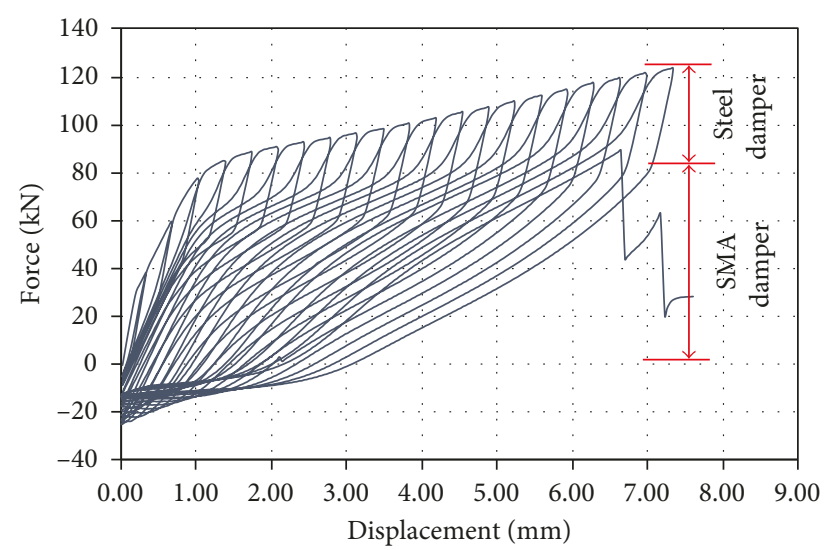

(d)

Figure 10: Force and displacement curves. (a) SMA-BR-1. (b) SMA-BR-2. (c) SMA-BR-3. (d) SMA-BR-4.

observe the changes in the energy dissipation and strength capacity. For example, the SMA-BR-1 model was designed without steel plate dampers while the SMA-BR-1 model was designed to use six steel plate dampers, three for each side. Displacement-controlled cyclic loads were imposed on the specimens at a rate of $0.033 \mathrm{~mm} / \mathrm{sec}$, in the form of a triangular wave. The detailed load hysteresis curve is presented in Figure 8. As the number of cycles increased, the amplitude of the displacement load was gradually augmented. Finally, the last cycle of the displacement load was applied up to $7.5 \mathrm{~mm}$. The measurement points were selected at the specific displacements (i.e., $1,3,5$, and $7 \mathrm{~mm}$ ), and then the load displacement curves were measured for each load cycle. In the next section, the results obtained from the experimental tests will be discussed.

\section{Experimental Test Results}

Steel and superelastic SMA plate dampers were installed at the center of the box-type bracing members, and then experimental tests were conducted by applying the displacement-controlled load history presented in Figure 8. The geometry of the bracing member and the fracture of the plate dampers after the completion of the experimental tests are shown in Figure 9. In the figures on the right, specimen numbers 1 and 3 indicate superelastic SMA plate dampers, while specimen numbers 2 and 4 represent the steel plate dampers. Steel possesses superior ductility compared to superelastic SMA in that it allows ultimate strain up to $25 \%$ without the occurrence of necking. Therefore, in an extreme state, the breakdown of the presented bracing system takes place due to a fracture of the superelastic SMA plate dampers. Due to the thickness of the steel plate dampers, local buckling tends to occur when compressive loads are applied to the bracing member.

Figure 10 shows the force and displacement curves for each of the experimental models, which were obtained from the cyclic loading tests. It can be observed in the figure that the postyield strength gradually increased along with the number of used steel plates. The SMA-BR-1 model without steel plate dampers had a load of only about $85 \mathrm{kN}$ at the $7 \mathrm{~mm}$ displacement, while the SMA-BR-4 model had a load of as much as $120 \mathrm{kN}$ at the same displacement. All the four models clearly exhibited a sudden drop in strength due to the fractures on the superelastic SMA damper after the application of a $6 \mathrm{~mm}$ displacement load. In the force and displacement curves of the steel plate dampers, the initial slope represented by the stiffness is the same as the unloading 


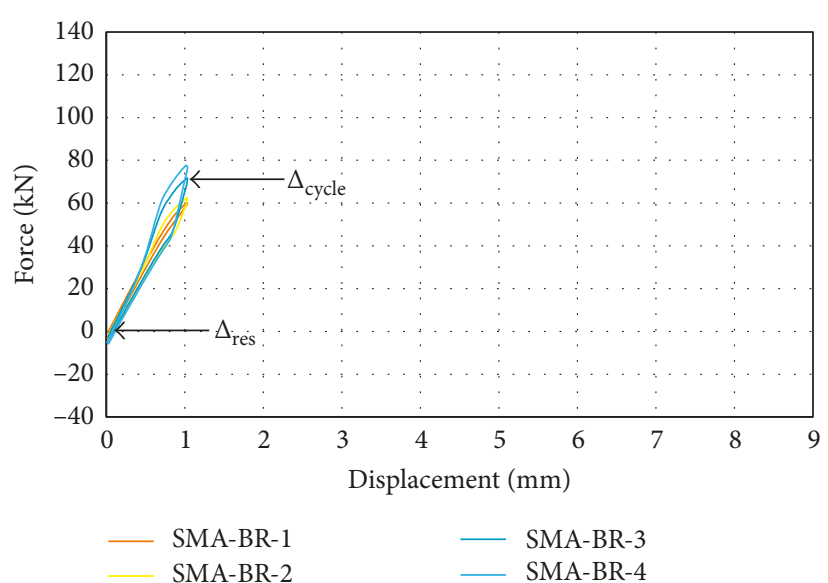

(a)

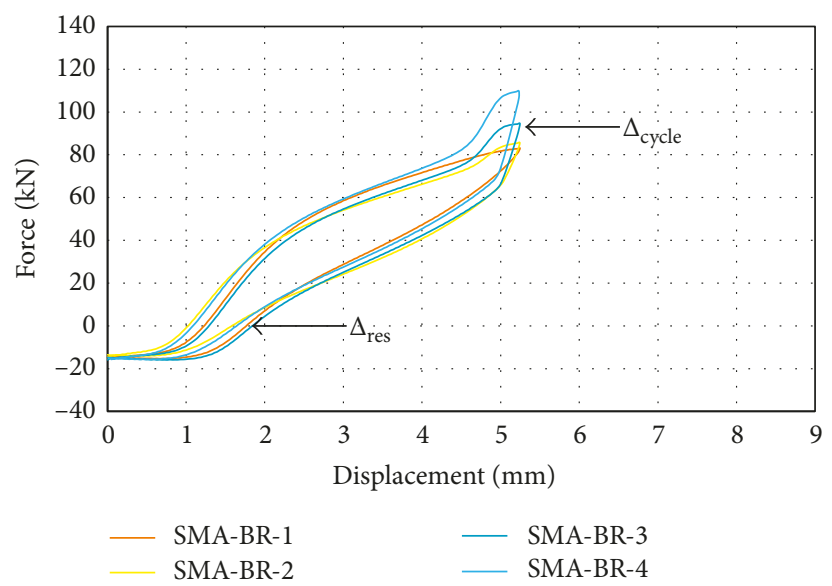

(c)

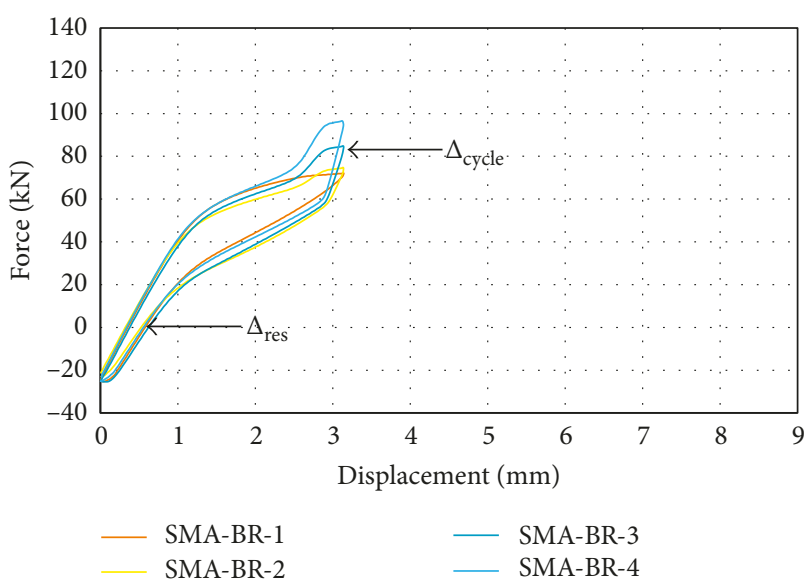

(b)

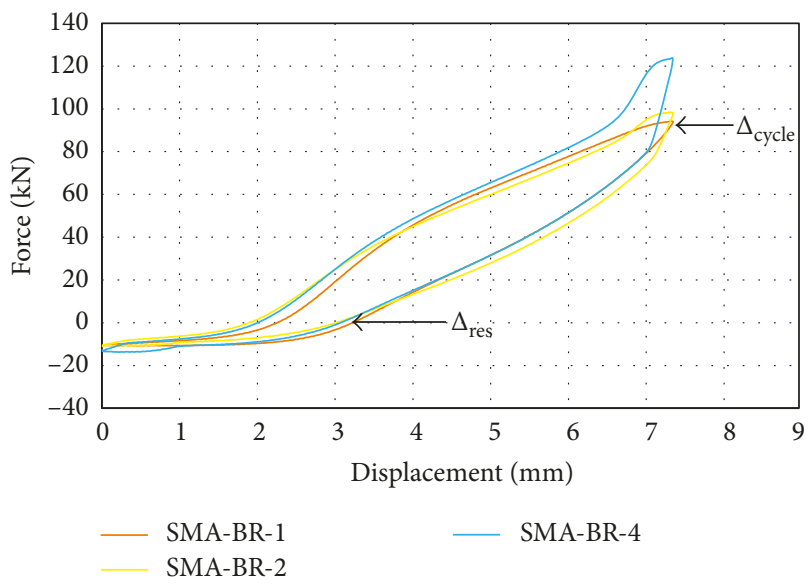

(d)

Figure 11: Force and displacement curves during loading cycles: S1 (1 mm) (a), S2 (3 mm) (b), S3 (5 mm) (c), and S4 (7 mm) (d) loading cycles.

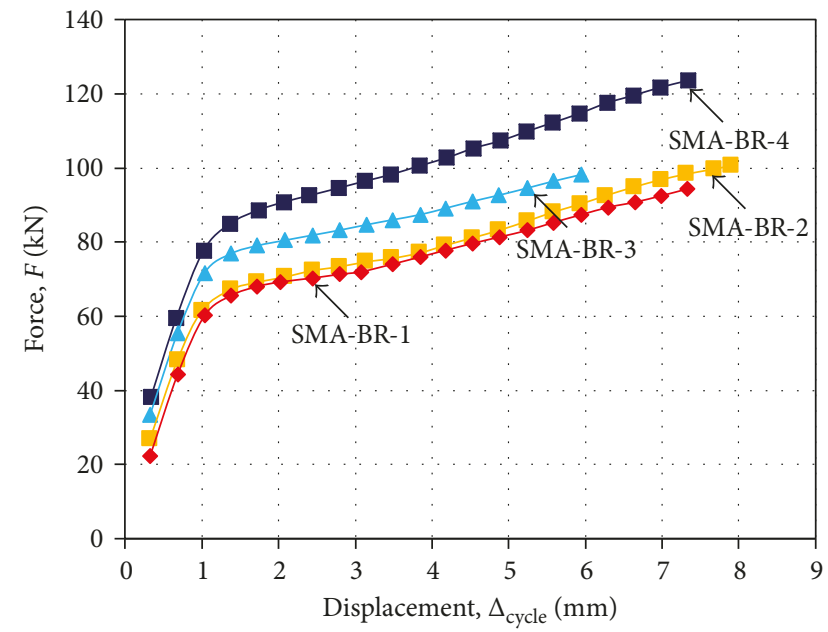

FIgURE 12: Comparison for loading forces along the measurement displacement loading cycles (SMA-BR model series).

slope, and thus restored displacement upon unloading is hardly displayed. This means that a considerable amount of residual displacement may be generated during a cyclic

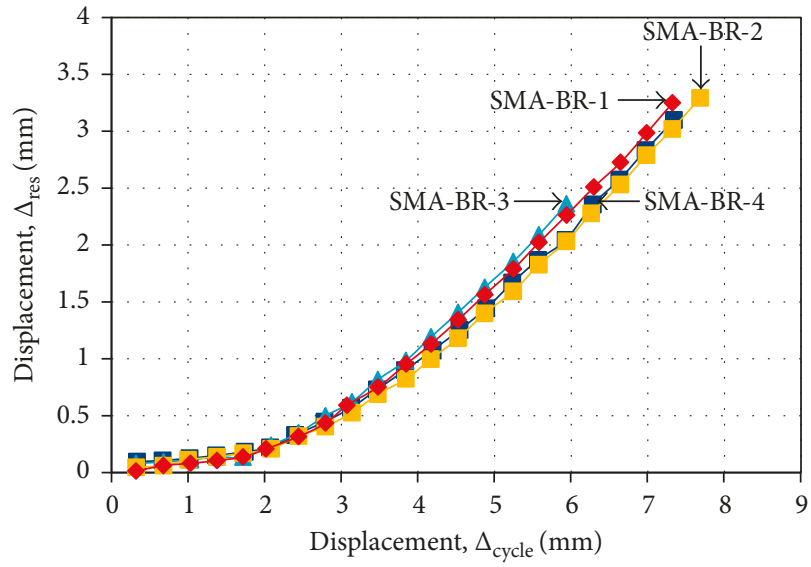

FIgURE 13: Comparison for residual displacements along the measurement displacement loading cycles (SMA-BR model series).

loading test. In the case of the proposed damper system, however, the residual displacements are remarkably reduced owing to the recentering effect attributed to the superelastic SMA plate dampers. In the unloading path of the SMA-BR-4 


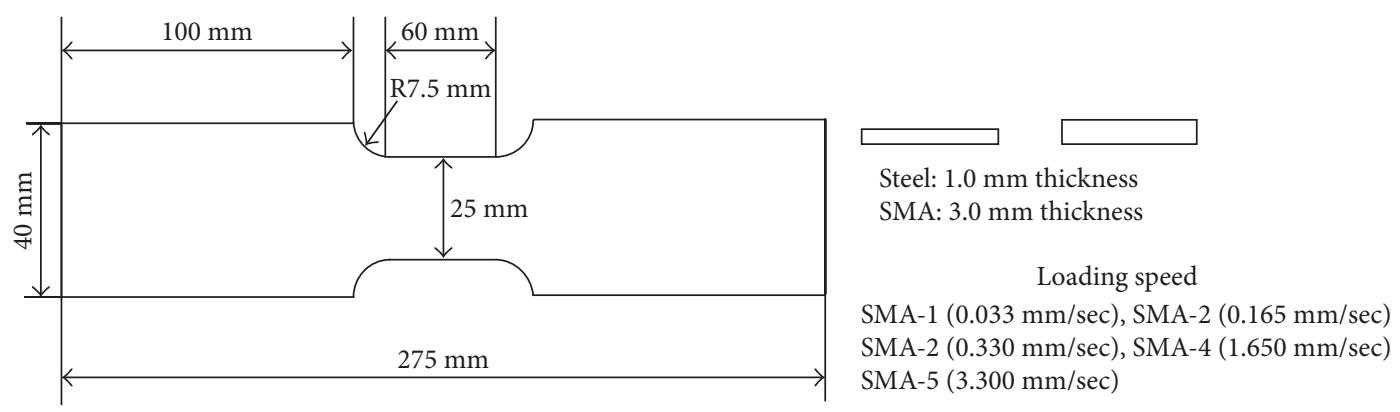

FIGURE 14: Specimens for the ASTM standard material tests.
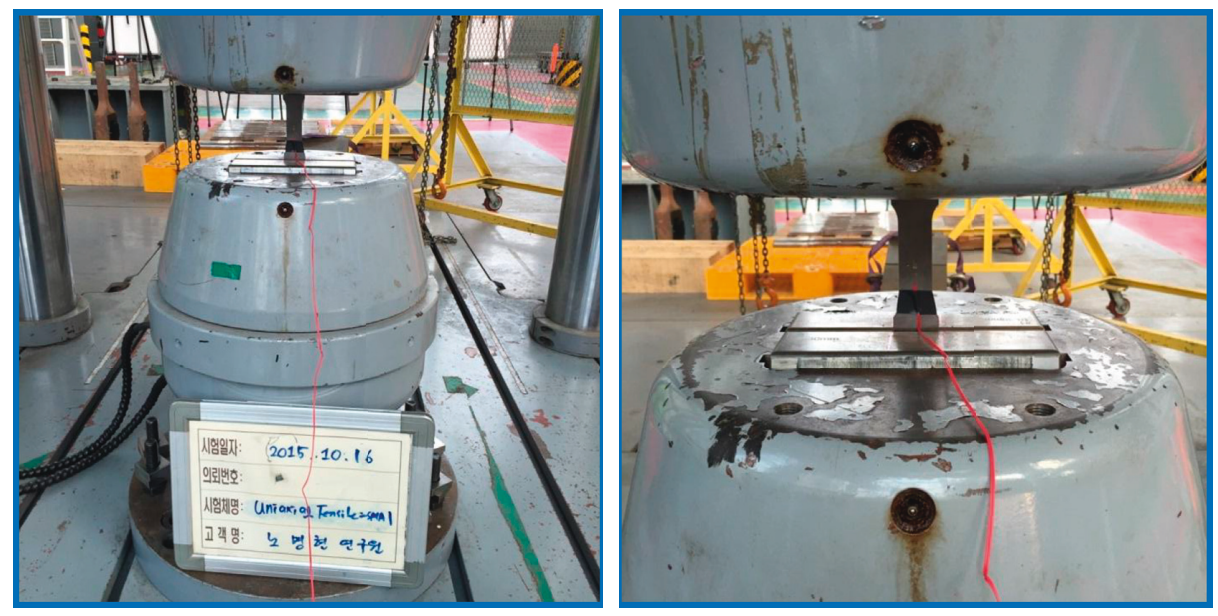

Figure 15: Material test setup.

model during the last loading cycle, the unloading slope is affected by the behavior of the steel plate damper until the unloading force is reduced to approximately $82 \mathrm{kN}$, which is close to the ultimate strength of the SMA-BR-1 model. Thereafter, this unloading slope can be affected by the behavior of the superelastic SMA dampers, thereby showing a restored displacement and a recentering mechanism (Figure 10(d)).

The force and displacement curves per loading cycle were measured based on the displacement measurement points presented in Figure 8 (i.e., S1, S2, S3, and S4), with the intention of evaluating the strength capacity as well as the residual displacement for each model (Figure 11). The force and displacement curves at the measurement point of $7 \mathrm{~mm}$ failed to be measured due to the fracture occurrence at the maximum displacement of about $6 \mathrm{~mm}$. All the four models exhibited elastic or very slight plasticity in the $1 \mathrm{~mm}$ displacement loading cycle $\left(\Delta_{\text {cycle }}\right)$, and it was confirmed that these four models could be restored to their original configuration without residual displacement $\left(\Delta_{\text {res }}\right)$ after the removal of the displacement load. It was observed that as the number of used steel plate dampers increased, not only the energy dissipation capacity represented by the areas of the force and displacement curves but also the strength capacity increased. In the initial stage of unloading, displacement recovery hardly occurs because the force is reduced with a steep slope. When the strength capacity decreases to the force provided by the steel plate damper, slope changes immediately occur upon unloading behavior. It is possible to observe gentle slope changes in the unloading path, arising due to the effect of using superelastic SMA plate dampers, and also to find recentering behavior in the force and displacement curves. It was confirmed that the proposed bracing damper could considerably reduce the residual deformation compared with the case of using only steel plate dampers. It was also observed that the degrees of residual deformation generated in the four models under the same displacement load cycle were almost the same even if the numbers of steel dampers that were used were different.

To clearly observe both the postyield strength and the residual deformation as the number of displacement-controlled loading cycles increases, Figures 12 and 13 show the corresponding loading forces and residual displacements, respectively. As shown in the said figures, the postyield strength increases along with the number of used steel plate dampers, as expected, but the occurrence of residual deformation showed that the four models were almost constant in the same displacement loading cycle. The amount of residual deformation occurs gently, with a yield of less than $0.5 \mathrm{~mm}$ until the displacement load of $3 \mathrm{~mm}$, and thereafter, residual deformation occurs up to about $3 \mathrm{~mm}$ with the slope of the straight line, up to a $7 \mathrm{~mm}$ displacement load. Based on the analysis of the 


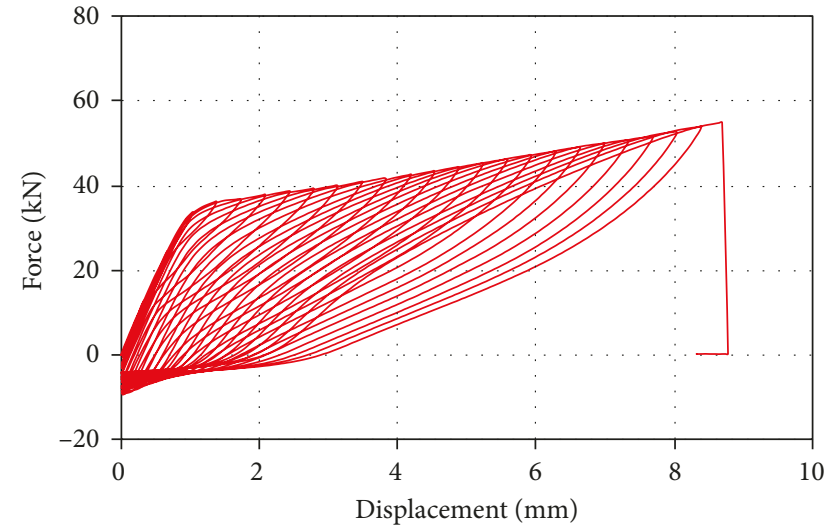

(a)

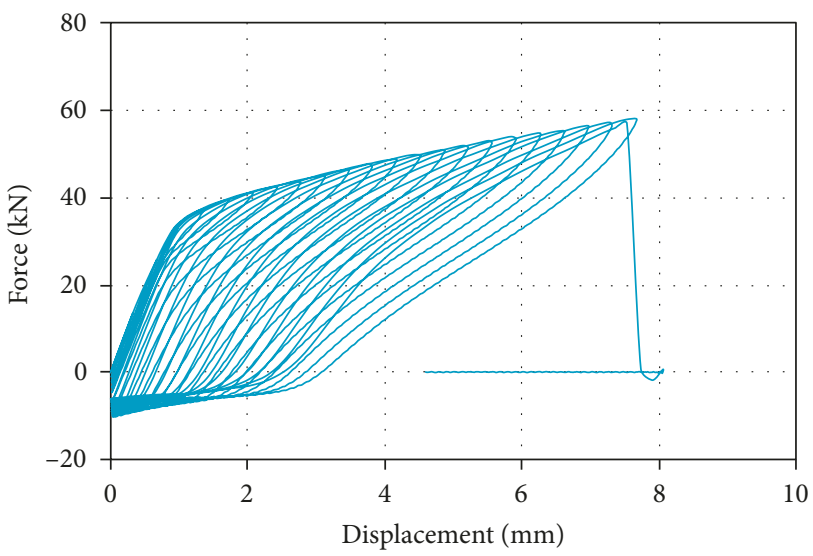

(c)

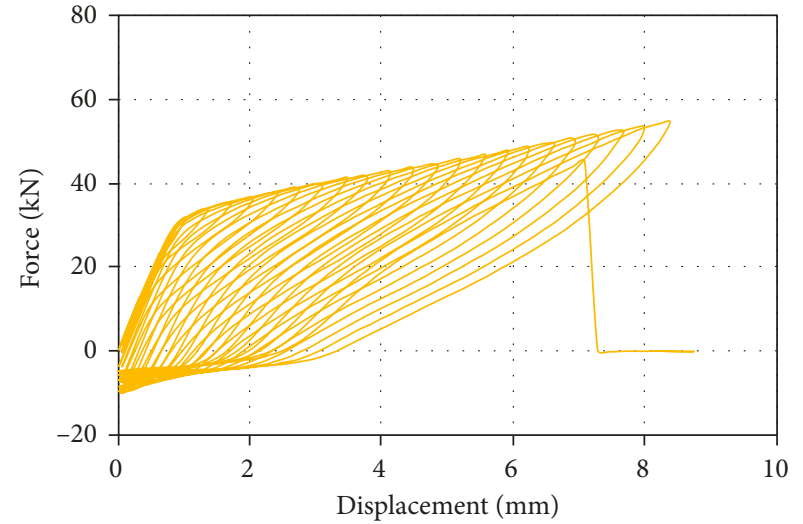

(b)

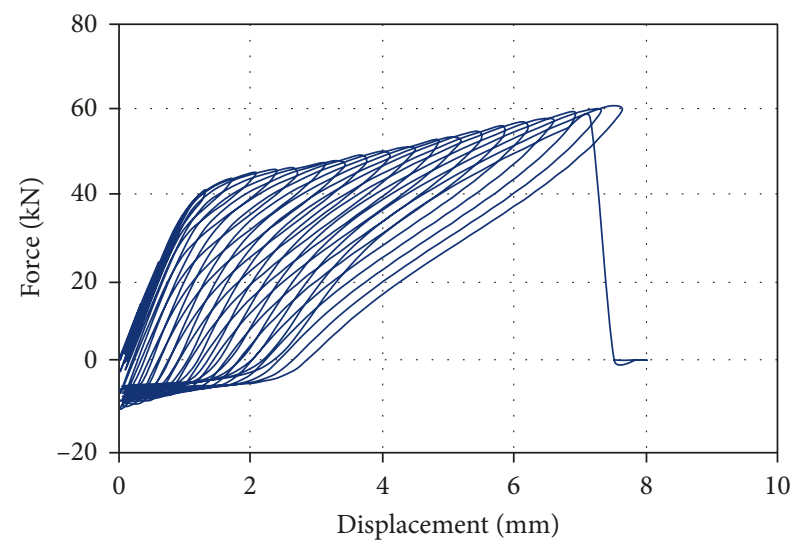

(d)

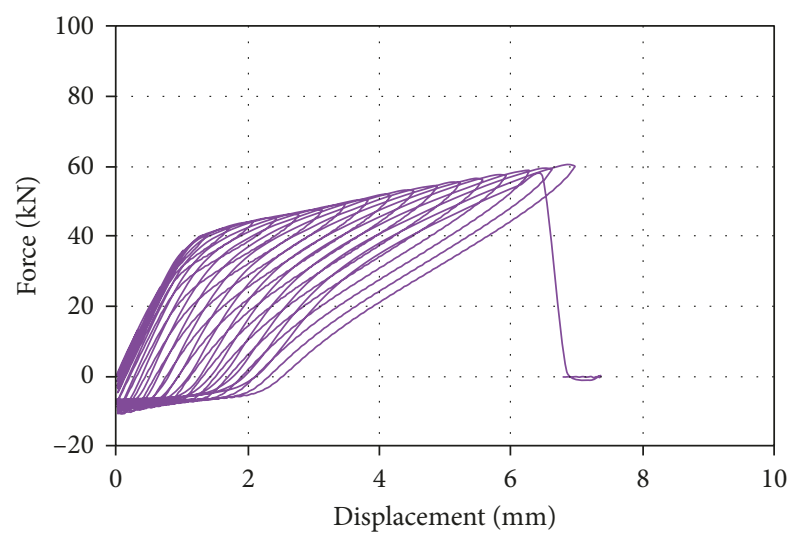

(e)

Figure 16: Force and displacement curves for SMA materials subjected to different loading speeds. (a) SMA-1 (0.033 mm/sec). (b) SMA-2 $(0.165 \mathrm{~mm} / \mathrm{sec})$. (c) SMA-3 $(0.330 \mathrm{~mm} / \mathrm{sec})$. (d) SMA-4 $(1.650 \mathrm{~mm} / \mathrm{sec}) .(\mathrm{e}) \mathrm{SMA}-5(3.300 \mathrm{~mm} / \mathrm{sec})$.

experimental results, the influence of each plate damper on the behavior of the bracing member was examined.

\section{Additional Material Test Results}

In the case of the bracing dampers presented in Section 5, the force and displacement curves were reproduced by applying pseudostatic cyclic displacement loads with a fixed loading speed. Thereafter, both the recentering force and the energy dissipation capacity were evaluated by analyzing these resulting curves. Besides, additional material tests were carried out to predict the behavior of the proposed bracing dampers with respect to energy dissipation and recentering when considering the dynamic 


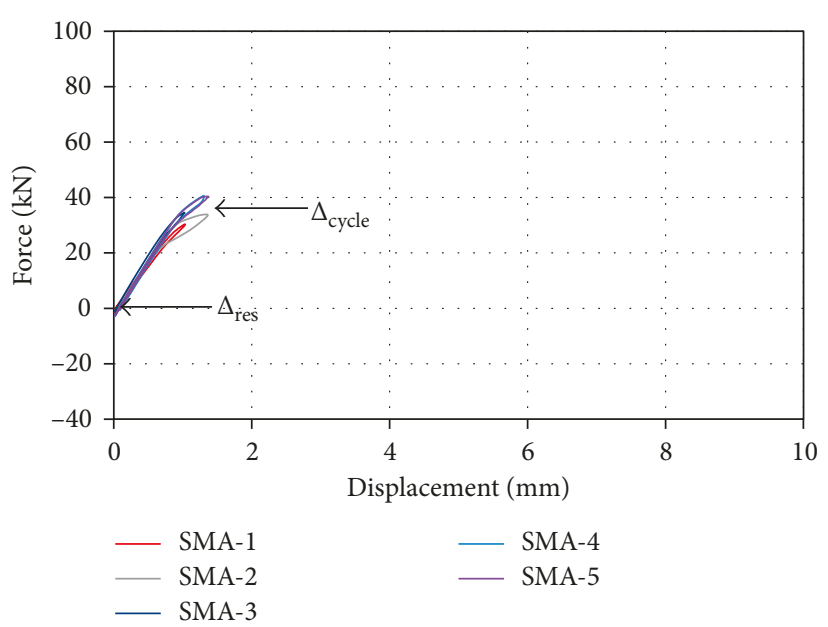

(a)

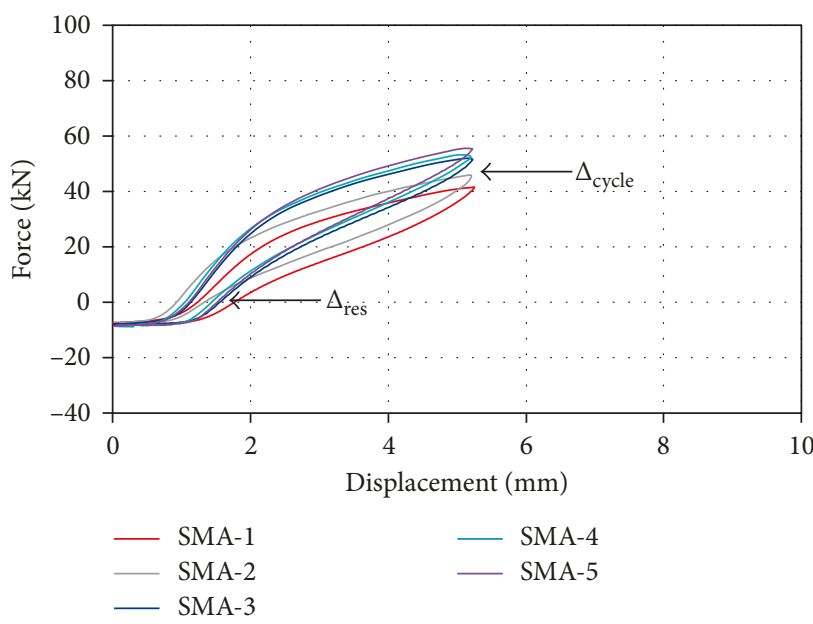

(c)

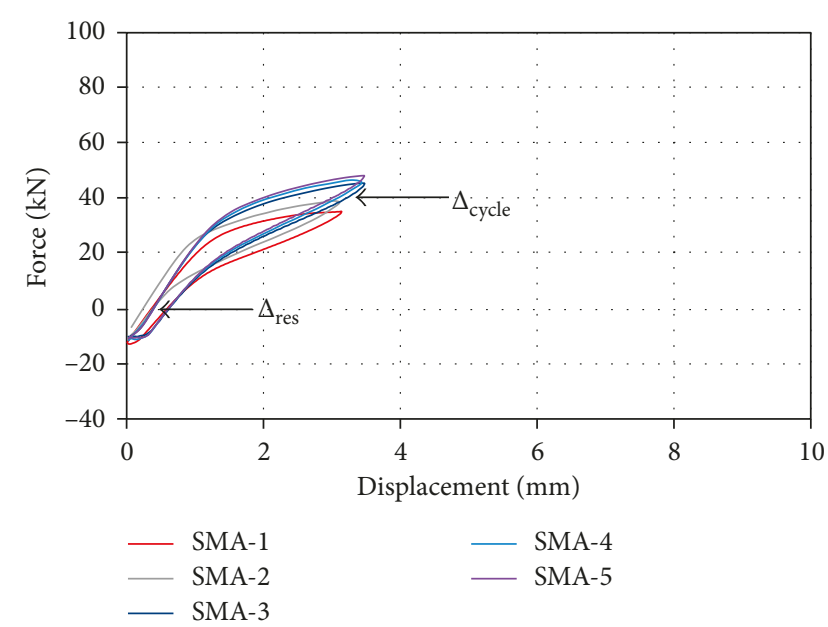

(b)

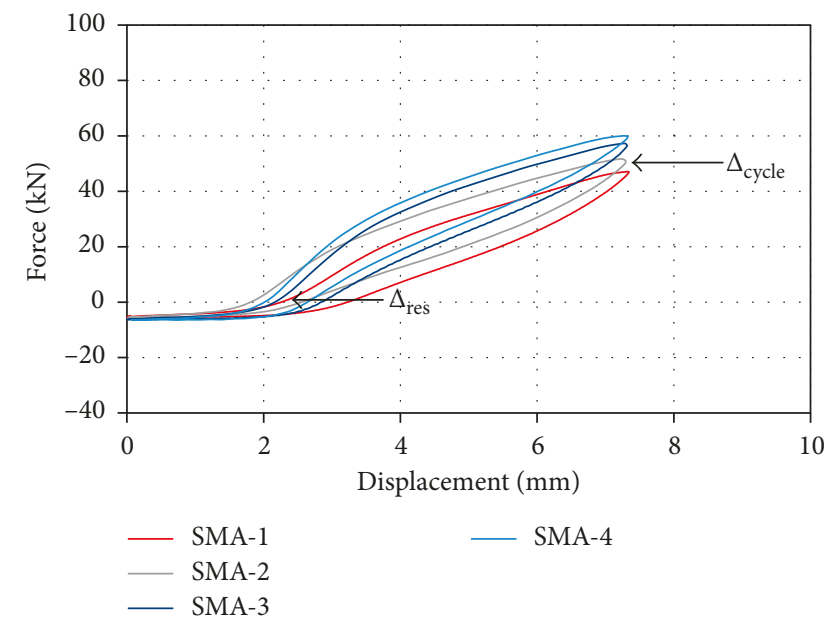

(d)

Figure 17: Force and displacement curves during loading cycles: S1 (1 mm) (a), S2 (3 mm) (b), S3 (5 mm) (c), and S4 (7 mm) (d) loading cycles.

effect with different loading speeds. Figure 14 shows the standard sizes of the steel and superelastic SMA material specimens manufactured according to the ASTM (American Standard Testing Method) regulations [27, 28], and Figure 15 shows the material specimen installed in the UTM (Universal Testing Machine) used for the dynamic loading tests at different loading speeds. The thickness of the material specimen was designed to be the same as that of the plate damper, and the steel and superelastic shape memory alloy plates were fabricated to have 1 and $3 \mathrm{~mm}$ thicknesses, respectively. The effective width at the center of the specimen, however, was slightly larger than that of the plate damper that was used for the brace member, and displacement-controlled loading tests were performed. To consider the effect of dynamic loading on the same material specimen, the experiment was carried out using the loading speed as a variable. Experimental material tests were performed on five specimens with $0.033,0.165$, $0.330,1.650$, and $3.300 \mathrm{~mm} / \mathrm{sec}$ loading speeds.
For the SMA-1 and Steel-1 models, material tests were performed by setting the load speed to $0.033 \mathrm{~mm} / \mathrm{sec}$, which is the same as that with the plate damper models installed on the bracing member. On the other hand, the material tests of the SMA-5 and Steel-5 models were carried out with a 100time faster loading speed $(3.300 \mathrm{~mm} / \mathrm{sec})$ compared with the basic SMA-1 and Steel-1 models. Based on the results of the material tests, the postyield strength, energy dissipation capacity, and recentering capability of each specimen were evaluated when the dynamic effects were considered. Figure 16 shows the force and displacement curves for the superelastic SMA material specimens subjected to different loading speeds. The SMA-1 model under a $0.033 \mathrm{~mm} / \mathrm{sec}$ loading speed showed an about $50 \mathrm{kN}$ force at a $7 \mathrm{~mm}$ displacement, while the SMA-5 model under a $3.300 \mathrm{~mm} / \mathrm{sec}$ loading speed showed as much as a $60 \mathrm{kN}$ force at the same displacement. As the test results of the SMA-5 model have conditions similar to those of the bracing damper subjected 


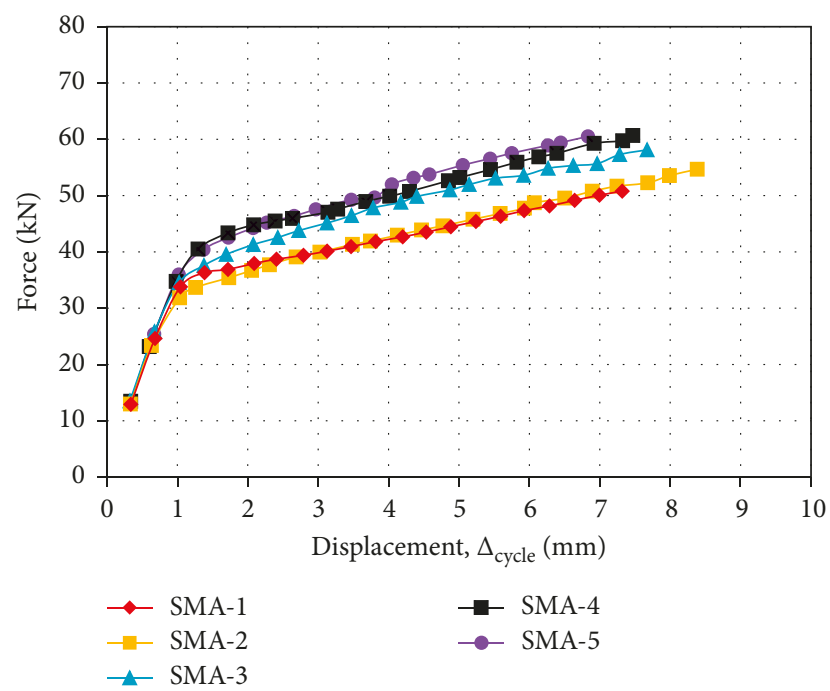

FIgURE 18: Comparison for loading forces along the measurement displacement loading cycles (SMA material model series).

to the earthquake load, an increase in the resistance force can be expected when an earthquake occurs, compared with the case where the static load is imposed. Due to the rapid loading speed, however, the SMA-5 model showed a sudden break at a displacement of approximately $7 \mathrm{~mm}$. On the other hand, the SMA-1 model showed that it could withstand up to $8.5 \mathrm{~mm}$ displacement without failure as it has almost the same loading state as the static load.

To clearly observe the residual displacement $\left(\Delta_{\text {res }}\right)$ and energy dissipation capacity for each displacement loading cycle $\left(\Delta_{\text {cycle }}\right)$ in the same way as in the experiment on the bracing damper, Figure 17 shows the force and displacement hysteresis behavior of the SMA-1 to SMA-5 models per displacement loading cycle. As the loading speed increased, the ultimate strength capacity also increased, but the energy dissipation capacity characterized by the area of the hysteresis curve did not show any discrepancy between the SMA-1 and SMA-2 models. In addition, the residual displacement that occurred when the loading speed increased at the same displacement loading cycle was gradually increased as well. The postyield strength and residual displacement in all the displacement loading cycles can be seen in Figures 18 and 19, respectively. As shown in Figure 18, the material models subjected to cyclic loads with a faster loading speed had relatively larger postyield strength under the same displacement loading cycles. For residual displacement, the SMA-2 model exhibited the least occurrence of residual displacement under the same displacement loading cycle, but the four other models produced almost the same residual displacement (Figure 19). The force and displacement hysteresis curves for the steel material specimens under different loading speeds are presented in Figure 20. The postyield strength and residual displacement in all the displacement loading cycles can be seen in Figures 21 and 22, respectively. Unlike the material specimens with superelastic SMAs, each steel specimen exhibited almost the same force and displacement curves irrespective of the loading speed.

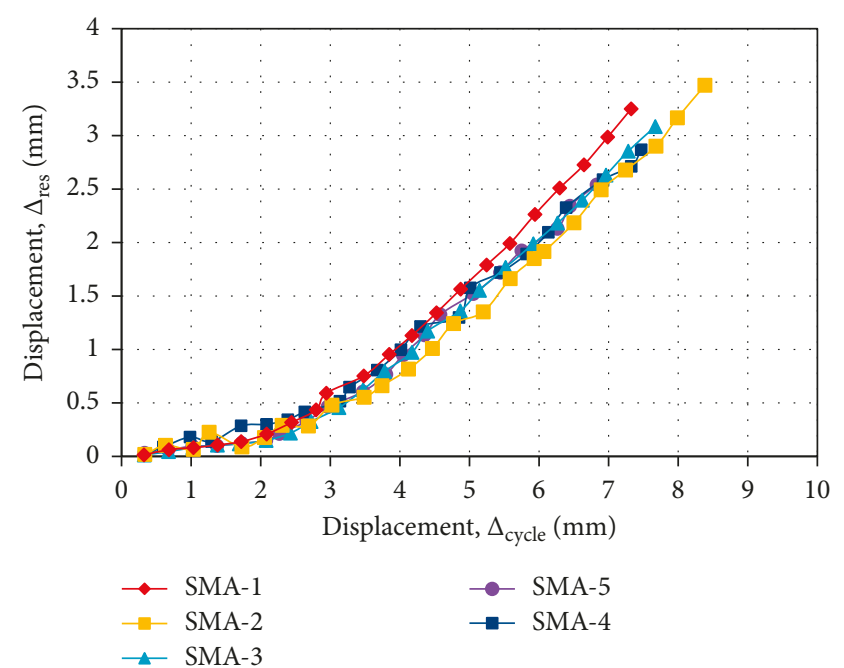

Figure 19: Comparison for residual displacements along the measurement displacement loading cycles (SMA material model series).

Therefore, it can be concluded that the loading speed has little influence on the occurrence of residual displacement and energy dissipation capacity in the bracing damper proposed herein, but it has a great influence on the change in the strength capacity of the superelastic SMA damper.

\section{Conclusions}

In this study, new damper systems that can be utilized as a bracing device by using superelastic shape memory alloy are proposed. A bracing damper made of a superelastic shape memory alloy (SMA) plate plays a role in reducing the occurrence of residual displacement by providing recentering to the bracing system. An additional steel plate damper was installed on the bracing device to improve the resistance strength and energy dissipation capacity. The superelastic SMA used in this study showed flag-shaped behavior when quasi-static cyclic loads were imposed by controlling the displacement at room temperature, so that the energy dissipation capacity attributed to the stress plateau, and the recentering force attributed to the phase change process upon unloading, could be observed. Owing to the inherent characteristics of this superelastic SMA, the bracing damper system proposed in this study improved not only the strength capacity but also the recentering compared with the conventional steel dampers. If superelastic SMA and steel plate dampers are used in combination with a bracing member, the amount of residual displacement generated will be the same as that of a bracing member provided with only a superelastic shape memory alloy plate damper, but it was confirmed through the test result obtained in this study that the strength performance and energy dissipation capacity simultaneously increased. To determine the effect of the dynamic load such as an earthquake, displacement-controlled cyclic loads were applied to the material specimen of the superelastic SMA with various loading speeds. As a result, the same level of residual 


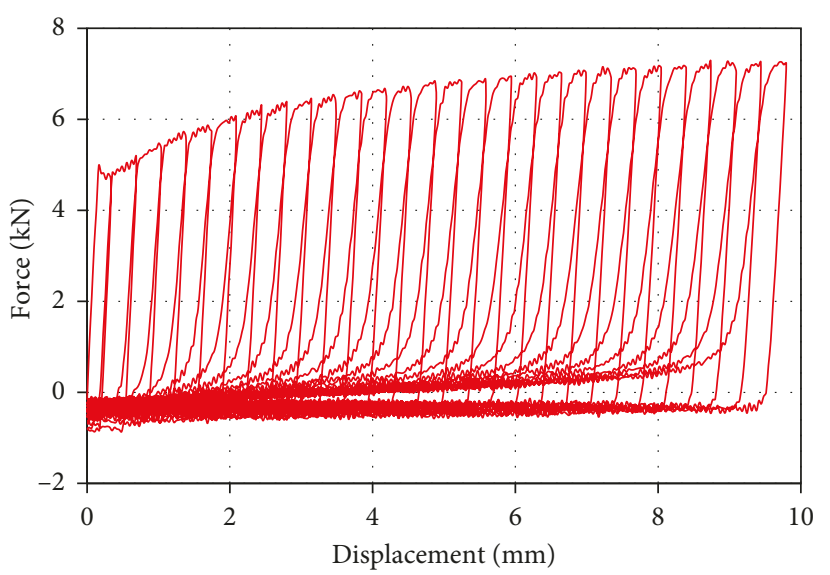

(a)

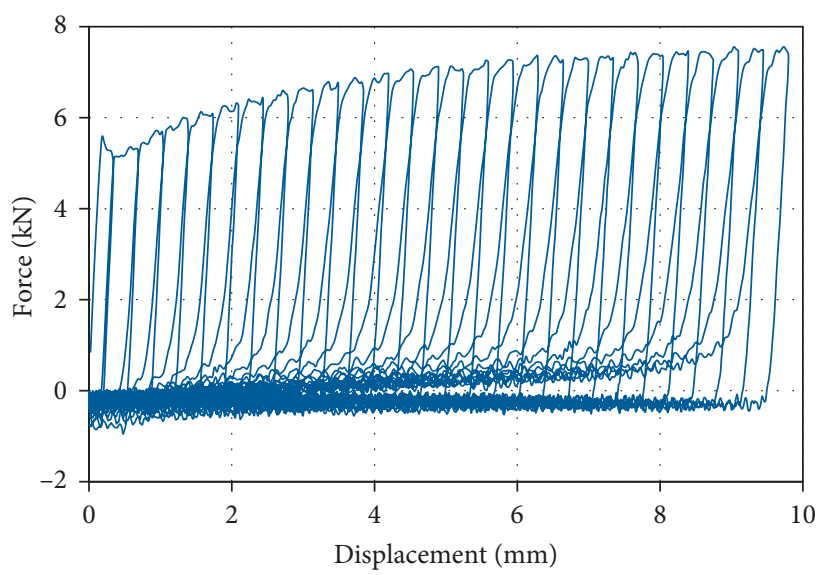

(c)

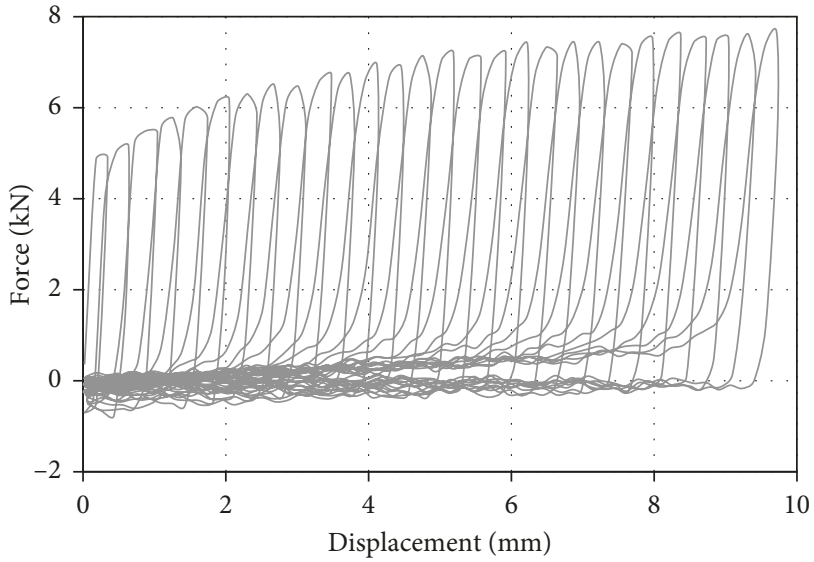

(b)

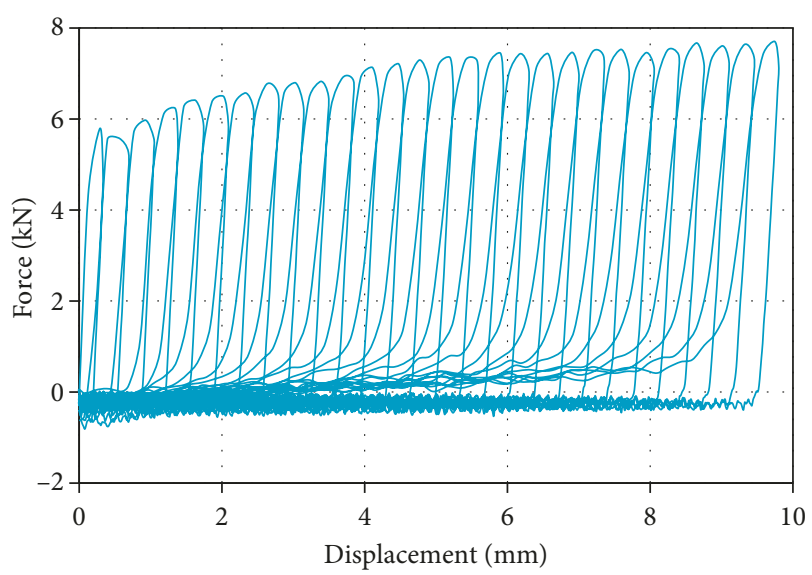

(d)

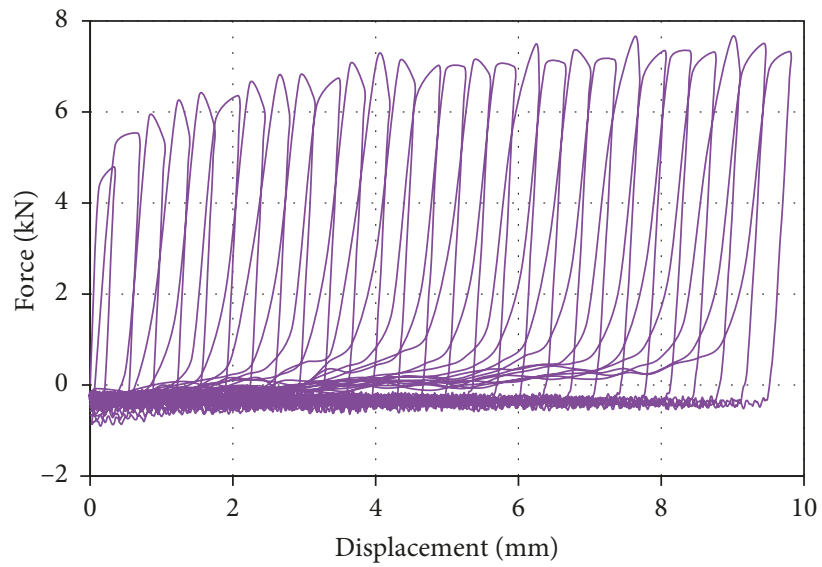

(e)

Figure 20: Force and displacement curves for steel materials subjected to different loading speeds. (a) Steel-1 (0.033 mm/sec). (b) Steel-2 $(0.165 \mathrm{~mm} / \mathrm{sec})$. (c) Steel-3 $(0.330 \mathrm{~mm} / \mathrm{sec})$. (c) Steel-4 $(1.650 \mathrm{~mm} / \mathrm{sec})$. (e) Steel-5 $(3.300 \mathrm{~mm} / \mathrm{sec})$.

displacement occurred at all the superelastic SMA specimens regardless of the loading speed. On the other hand, as the applied loading speed increased, the resistance strength proportionally increased after yielding. For the steel specimens, their force and displacement curves were almost the same regardless of the loading speeds. Based on the results of this study, it can be concluded that the bracing damper system proposed herein can be used more effectively with respect to the resistance strength under a seismic load with a fast loading speed rather than a slow static load. In this 


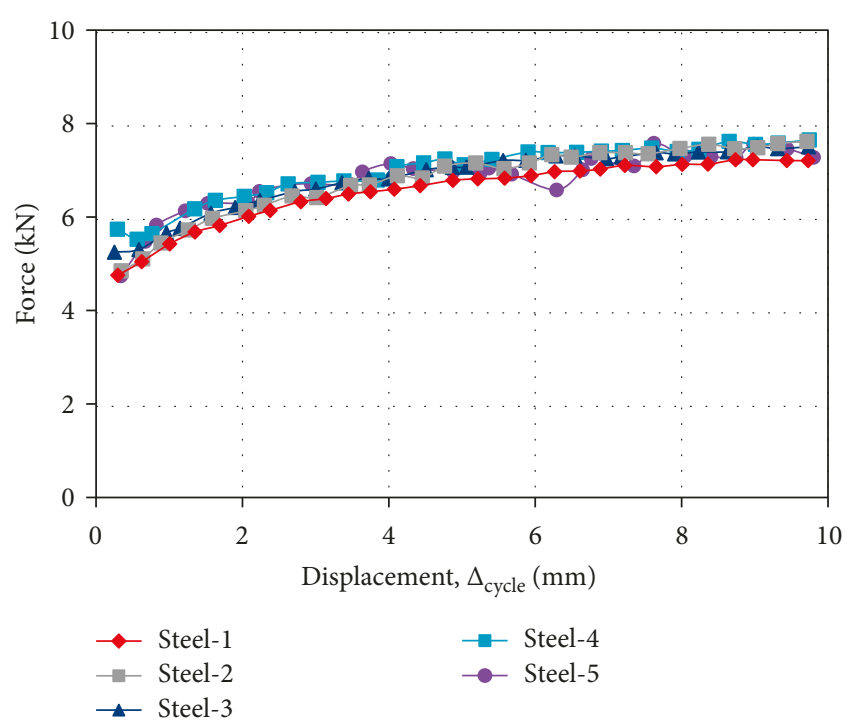

FIGURE 21: Comparison for loading forces along the measurement displacement loading cycles (steel material model series).

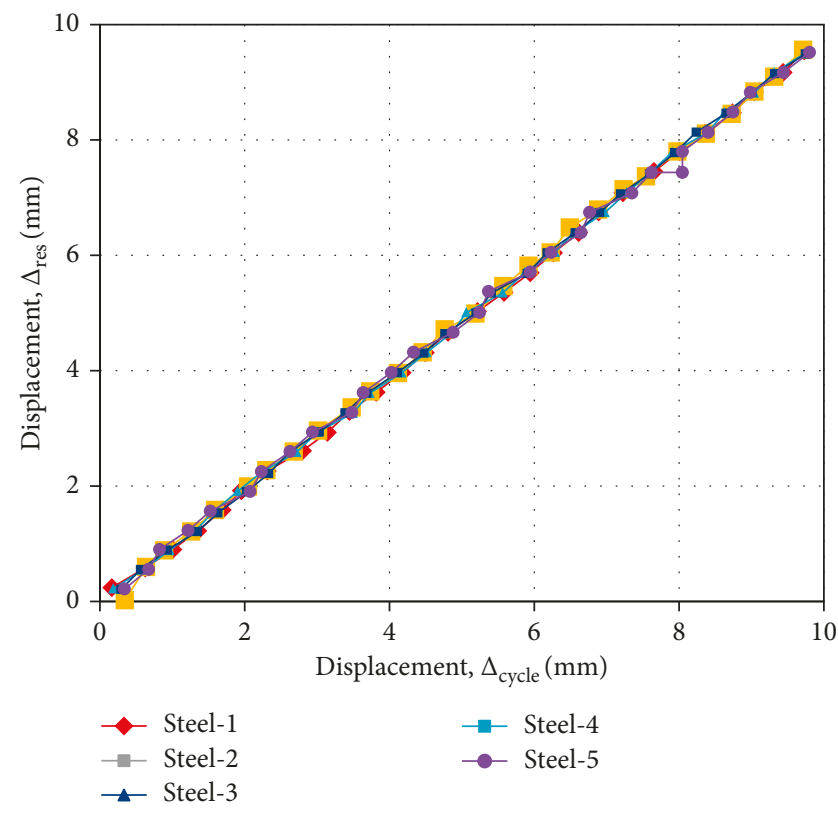

Figure 22: Comparison for residual displacements along the measurement displacement loading cycles (steel material model series).

study, different loading speeds were imposed on only material models as a matter of cost, and the material test results were compared. For the future study, more experimental tests must be conducted on bracing models with various loading speeds to very accurately predict their strength and recentering capacity.

\section{Conflicts of Interest}

The authors declare that they have no conflicts of interest.

\section{Acknowledgments}

This research was supported by a grant (17CTAP-C12981101) from Land Transport Technology Promotion Research Project Program funded by the Ministry of Land, Infrastructure and Transport of Korean Government. This work (Grant no. C0540654) was also supported by Business for R\&D funded by The Korea Ministry of SMEs (Small and Medium Enterprises) and Startups in 2017.

\section{References}

[1] J. Seo and J. W. Hu, "Seismic response and performance evaluation of self-centering LRB isolators installed on the CBF building under NF ground motions," Sustainability, vol. 8, no. 2, p. 109, 2016.

[2] J. W. Hu, "Response of seismically isolated steel frame buildings with sustainable lead-rubber bearing (LRB) isolator devices subjected to near-fault (NF) ground motions," Sustainability, vol. 7, no. 1, pp. 111-137, 2015.

[3] V. A. Matssgar and R. S. Jangid, "Influence of isolator characteristics on the response of base-isolated structures," Engineering Structures, vol. 26, no. 12, pp. 1735-1749, 2004.

[4] P. Castaido and M. De Iuliis, "Optimal integrated seismic design of structural and viscoelastic bracing-damper systems," Earthquake Engineering \& Structural Dynamics, vol. 43, pp. 1809-1827, 2014.

[5] P. S. Lobo, J. Almeida, and L. Guerreiro, "Semi-active damping device based on superelastic shape memory alloys," Engineering Structures, vol. 3, pp. 1-12, 2015.

[6] B. Silwal, R. J. Michael, and O. E. Ozbulut, "A superelastic viscous damper for enhanced seismic performance of steel moment frames," Engineering Structures, vol. 105, pp. 152-164, 2015.

[7] D. J. Miller, L. A. Fahnestock, and M. R. Eatherton, "Development and experimental validation of a nickel-titanium shape memory alloy self-centering buckling-restrained brace," Engineering Structures, vol. 40, pp. 288-298, 2012.

[8] D. R. Sahoo and S. H. Chao, "Performance-based plastic design method for buckling-restrained frames," Engineering Structures, vol. 32, no. 9, pp. 2950-2958, 2010.

[9] B. Asgarian and S. Moradi, "Seismic response of steel braced frames with shape memory alloy braces," Journal of Constructional Steel Research, vol. 67, no. 1, pp. 65-74, 2011.

[10] T. Y. Yang, Y. Li, and S. Leelataviwat, "Performance-based design and optimization of buckling restrained knee braced truss moment frame," Journal of Performance of Constructed Facilities, vol. 28, no. 6, p. A4014007, 2014.

[11] C. X. Qiu and S. Zhu, "High-mode effects on seismic performance of multi-story self-centering braced steel frames," Journal of Constructional Steel Research, vol. 119, pp. 133-143, 2016.

[12] H. Ma and M. C. H. Yam, "Modelling of a self-centring damper and its application in structural control," Journal of Constructional Steel Research, vol. 67, no. 4, pp. 656-666, 2011.

[13] M. A. Farmani and M. Ghassemieh, "Shape memory alloybased moment connections with superior self-centering properties," Smart Materials and Structures, vol. 25, no. 7, p. 075028, 2016.

[14] S. Moradi and M. S. Alam, "Feasibility study of utilizing superelastic shape memory alloy plates in steel beam-column connections for improved seismic performance," Journal of Intelligent Material Systems and Structures, vol. 26, no. 4, pp. 463-475, 2016. 
[15] M. S. Speicher and R. DesRoches, "Experimental results of NiTi shape memory alloy (SMA)-based beam-column connection," Engineering Structures, vol. 33, no. 9, pp. 2448-2457, 2011.

[16] J. W. Hu, E. Choi, and R. T. Leon, "Design, analysis, and application of innovative composite PR connections between steel beams and CFT columns," Smart Materials and Structures, vol. 20, pp. 25019-25033, 2011.

[17] J. W. Hu and R. T. Leon, "Analysis and evaluations for composite-moment frames with SMA PR-CFT connections," Nonlinear Dynamics, vol. 65, pp. 433-455, 2011.

[18] J. W. Hu, "Investigation on the cyclic response of superelastic shape memory alloy (SMA) slit damper devices simulated by quasi-static finite element (FE) analyses," Materials, vol. 7, no. 2, pp. 1122-1141, 2014.

[19] R. DesRoches, B. Taftali, and B. R. Ellingwood, "Seismic performance of steel frames with shape memory alloy connections, part I-analysis and seismic demands," Journal of Earthquake Engineering, vol. 14, no. 4, pp. 471-486, 2010.

[20] C. S. W. Yang, R. DesRoches, and R. T. Leon, "Design and analysis of braced frames with shape memory alloy and energy-absorbing hybrid devices," Engineering Structures, vol. 32, no. 2, pp. 498-507, 2010.

[21] M. Omar, "Seismic response of braced steel frames with shape memory alloy and mega bracing systems," World Academy of Science, Engineering and Technology. International Journal of Computer and Systems Engineering, vol. 8, pp. 131-138, 2014.

[22] C. X. Qiu and S. Zhub, "Performance-based seismic design of self-centering steel frames with SMA-based braces," Engineering Structures, vol. 130, pp. 67-82, 2017.

[23] C. W. Yang and D. DesRoches, "Bridges with innovative buckling restrained SMA expansion joints having a high symmetrical tension/compression capacity," in Proceedings of the Structures Congress 2015, pp. 452-461, Portland, Oregon, April 2015.

[24] N. Gao, J. S. Jeon, D. E. Hodgson, and R. DesRoches, “An innovative seismic bracing system based on a superelastic shape memory alloy ring," Smart Materials and Structures, vol. 25, p. 055030, 2016.

[25] A. B. M. Rafiqul Haque and M. S. Alam, "Hysteretic behaviour of a piston based self-centering (PBSC) bracing system made of superelastic SMA bars-a feasibility study," Engineering Structures, vol. 12, pp. 102-114, 2017.

[26] F. H. Dezfuli and M. S. Alam, "Smart lead rubber bearings equipped with ferrous shape memory alloy wires for seismically isolating highway brides," Journal of Earthquake Engineering, pp. 1-26, 2017.

[27] ASTM Standard ASTM A370-17, Standard Test Methods and Definitions for Mechanical Testing of Steel Products, American Society for Testing and Materials, West Conshohocken, PA, USA, 2006.

[28] ASTM Standard A356/A356M, Specification for Steel Castings, Carbon, Low Alloy, and Stainless Steel, Heavy-Walled for Steam Turbines, American Society for Testing and Materials, West Conshohocken, PA, USA, 2006. 


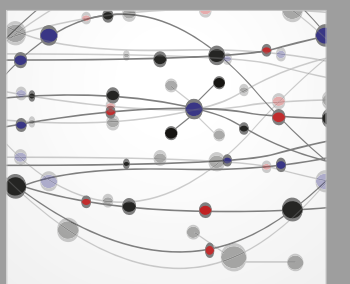

The Scientific World Journal
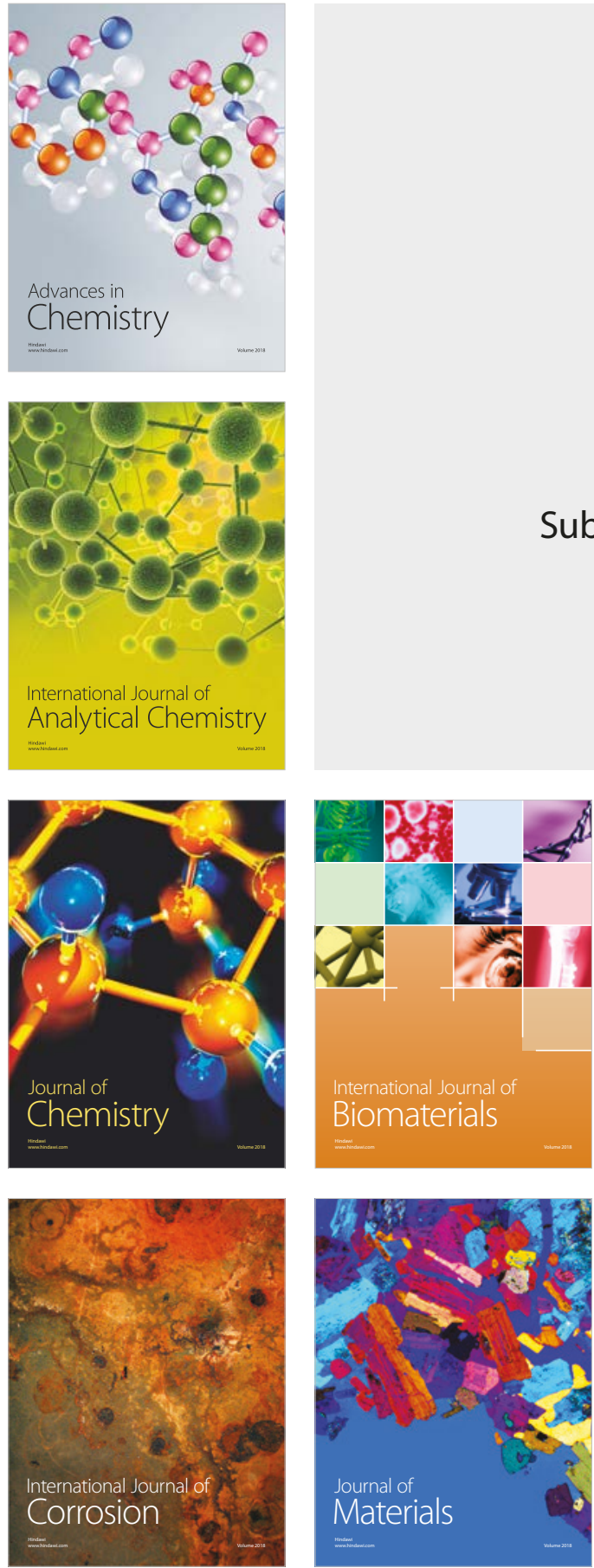

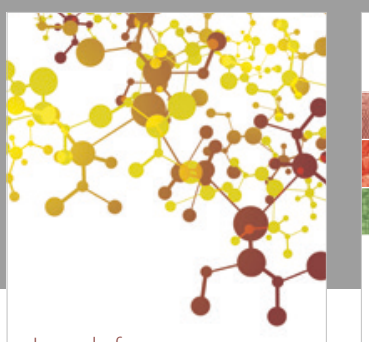

Journal of

Applied Chemistry
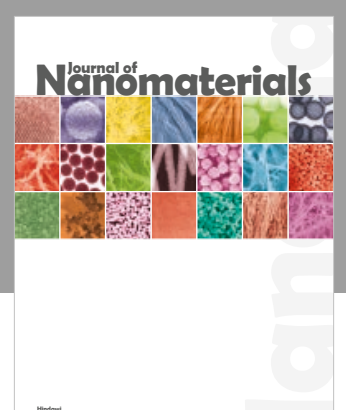

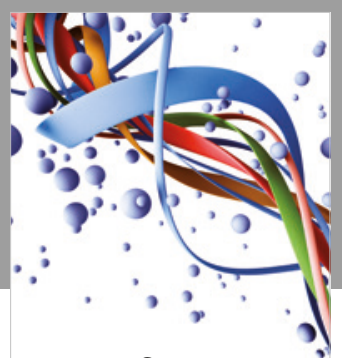

Scientifica

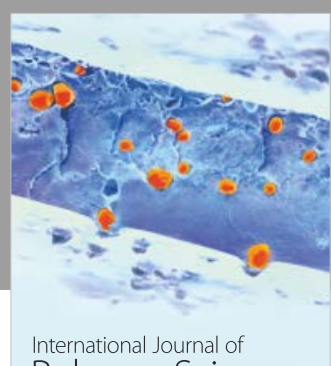

Polymer Science

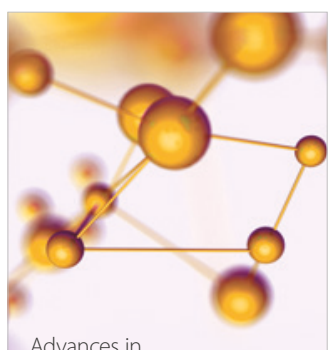

Physical Chemistry
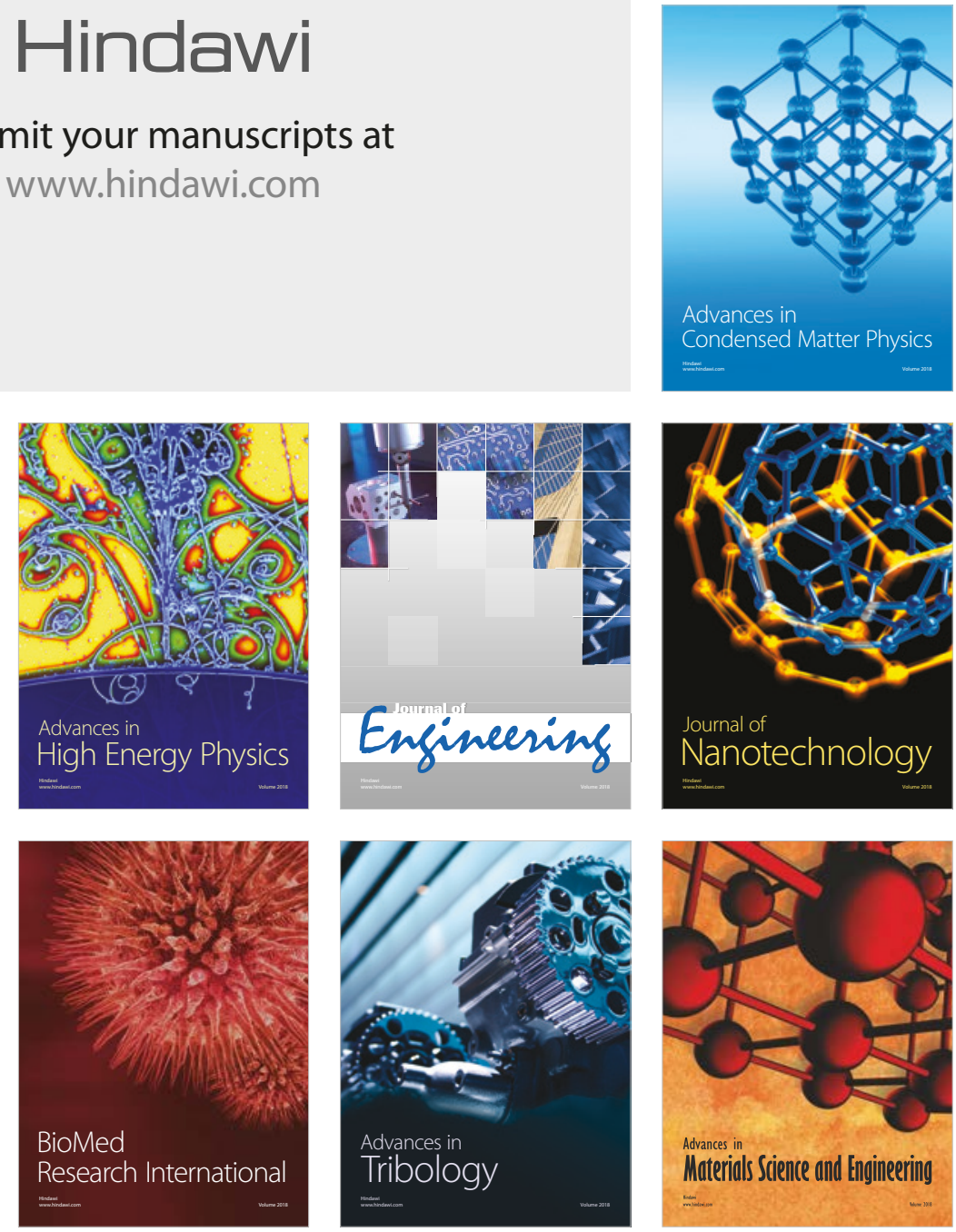